Federal Reserve Bank of Minneapolis

Research Department Staff Report 469

Revised June 2013

\title{
Careers in Firms: Estimating a Model of Learning, Job Assignment, and Human Capital Acquisition*
}

\author{
Elena Pastorino \\ Federal Reserve Bank of Minneapolis \\ and University of Minnesota
}

\begin{abstract}
This paper develops and structurally estimates a labor market model that integrates job assignment, learning, and human capital acquisition to account for the main patterns of careers in firms. A key innovation is that the model incorporates workers' job mobility within and between firms, and the possibility that, through job assignment, firms affect the rate at which they acquire information about workers. The model is estimated using longitudinal administrative data on managers from one U.S. firm in a service industry (the data of Baker, Gibbs, and Holmström (1994a,b)) and fits the data remarkably well. The estimated model is used to assess both the direct effect of learning on wages and its indirect effect through its impact on the dynamics of job assignment. Consistent with the evidence in the literature on comparative advantage and learning, the estimated direct effect of learning on wages is found to be small. Unlike in previous work, by jointly estimating the dynamics of beliefs, jobs, and wages imposing all of the model restrictions, the impact of learning on job assignment can be uncovered and the indirect effect of learning on wages explicitly assessed. The key finding of the paper is that the indirect effect of learning on wages is substantial: overall learning accounts for one quarter of the cumulative wage growth on the job during the first seven years of tenure. Nearly all of the remaining growth is from human capital acquisition. A related novel finding is that the experimentation component of learning is a primary determinant of the timing of promotions and wage increases. Along with persistent uncertainty about ability, experimentation is responsible for substantially compressing wage growth at low tenures.
\end{abstract}

Keywords: Careers; Job Mobility; Experimentation; Bandit; Human Capital; Wage Growth JEL Classification: D22, D83, J24, J31, J44, J62

*I am truly indebted to Ken Wolpin for his generous advice. I benefited from numerous conversations with John Geweke and Petra Todd. Chris Ferrall, Robert Gibbons, Hiro Kasahara, Michael Keane, John Moore, and Michael Waldman have offered especially valuable comments. Finally, I thank George Baker for kindly providing me with the data and Bengt Holmström for his support of the project. The views expressed herein are those of the author and not necessarily those of the Federal Reserve Bank of Minneapolis or the Federal Reserve System. 
The literature on careers in firms studies the allocation of workers to tasks and jobs within a firm and the dynamics of wages with tenure. Observationally, workers usually advance from lowerto higher-level jobs of a firm's hierarchy over time, wages on average increase with tenure in a firm, especially through promotions, but wage decreases are also common, mostly in response to unsuccessful performance. (See Gibbons and Waldman (1999a,b, 2006), hereafter GW, and Waldman (2012).) Models that are qualitatively successful at explaining these patterns combine job assignment, learning, and human capital acquisition. ${ }^{1}$ One feature that has generally been missing in the literature on careers is experimentation within firms: information on worker productivity is assumed to be passively acquired independently of a worker's job. The differential learning possibilities associated with different jobs within a firm can, however, have important implications for firms' job assignment decisions. (See Prescott and Visscher (1980) and Holmström and Tirole (1989) for early references.) Another element that the literature on careers has often ignored is worker mobility between firms and the impact of competition among firms on internal job assignment and compensation. This paper is the first to provide a comprehensive examination of the empirical relevance of these models of careers, of the relative importance of their components, and of the role of these missing elements.

Specifically, this paper develops and structurally estimates a model of the labor market with experimentation and turnover that integrates elements of correlated learning as in Jovanovic and Nyarko (1997), human capital acquisition as in Keane and Wolpin (1997), and careers in firms as in GW. The model is estimated using administrative data on managers from a single U.S. firm in a service industry (the data of Baker, Gibbs, and Holmström (1994a,b), hereafter BGH), which contain information about each manager's yearly job assignment, salary, and performance. A key advantage of the data is that the detailed performance information identifies the process for learning at each job in the firm. The tenure profiles of managers' job assignments and wages separately identify the process for human capital acquisition at each job. These data allow me to estimate the informativeness of the firm's jobs, determine the implied speed of learning at each job, and assess the contribution of learning and human capital acquisition to wage growth on the job.

At the estimated parameters, the model implies that learning is a quantitatively important source of observed career paths, unlike common estimates in the literature on comparative advantage and learning, as in Gibbons, Katz, Lemieux, and Parent (2005), Lluis (2005), and Hunnes (2012). Conceptually, these papers measure the direct and contemporaneous dependence of wages on beliefs about ability by assessing the impact of learning on the estimated effect of current characteristics of workers and jobs on current wages. This direct effect of learning on wages is estimated based on the wage process alone, instrumented to correct for the endogeneity of job assignment, and typically found to be small or insignificant or difficult to reconcile with economic intuition. In sharp contrast,

\footnotetext{
${ }^{1}$ That learning and human capital acquisition are primary determinants of observed earnings-experience profiles has recently been argued by Rubinstein and Weiss (2007). See Bagger, Fontaine, Postel-Vinay, and Robin (2011) for a detailed assessment of the contribution of search and human capital acquisition to individual wage growth.
} 
by explicitly estimating the joint dynamics of beliefs, job assignments, and wages implied by the model, here I am able to assess both the direct effect of learning on wages and its indirect effect due to its impact on the dynamics of job assignment. Intuitively, the indirect effect of learning on wages arises because learning leads managers to be more quickly promoted to higher levels of the job hierarchy over time, at which they are paid higher wages. Consistent with the literature, I find the direct effect of learning on wages to be small. ${ }^{2}$ Critically, however, I find its indirect effect to be much larger than the direct one. I estimate that learning contributes to more than one quarter of cumulative wage growth on the job during the first seven years of tenure, with the remaining growth explained by human capital acquisition. ${ }^{3}$ This finding implies a revised view of the role of learning for wages: the impact of learning on wages is substantial, but this effect is dynamic, operating indirectly though job promotions rather than through a direct static effect. Another key finding of this paper is that the different speed of learning at different jobs, that is, the experimentation component of learning, is a primary determinant of the timing of promotions and wage increases, which leads to a compression of wages at low tenures. Without experimentation, learning would account for an even greater contribution to wage growth.

In the model, production in firms is organized among distinct jobs to which workers are assigned. Initially, a worker's ability is unobserved, but over time all firms and the worker learn about ability by observing the worker's performance. When employed, workers also acquire human capital, which can be task- and firm-specific to varying degrees. (See Sanders and Taber (2012) on the importance of task-specific human capital for wage growth.) Jobs differ in the output they generate and in the information they provide about ability. Hence, the speed of learning differs across jobs. As a consequence, when assigning a worker to a job, firms trade off current output against the value of information and future human capital. Likewise, when comparing employment at different firms, workers weigh current wages against the value of information and future human capital. Thus, both firms and workers face a classic multi-armed bandit problem with dependent arms. ${ }^{4}$

I assume that in the market for managers, firms compete in jobs and wages in a Bertrand fashion. This formulation allows all firms to be heterogeneous in their technologies and thus imperfectly competitive, but it also nests GW's framework of firms with identical technologies. Heterogeneity in technologies generates not only wage dispersion among workers at any point in time but also worker turnover over time as workers move to firms with technologies that best match their partially learned ability and acquired human capital. With heterogeneity, equilibrium endogenously determines a flexible sharing rule of the surplus generated by a firm and a worker that does not restrict a worker to

\footnotetext{
${ }^{2}$ By replicating the analysis of Lluis (2005) and Hunnes (2012) in my data, based on the same instrumental variable approach as in Gibbons et al. (2005), I find that the impact of learning is negligible and insignificant. These estimates, though, do not capture the total effect of learning on wages. Details are available upon request.

${ }^{3}$ Similarly, Bagger et al. (2011) estimate that human capital acquisition accounts for $50 \%$ to $70 \%$ of the wage growth of individuals with 10 to 20 years of labor market experience.

${ }^{4}$ Jovanovic (1979), Miller (1984), and Flinn (1986) provide influential applications of the bandit problem with independent arms to labor market and occupational turnover.
} 
be paid his expected output at the employing firm. By measuring the difference between estimated output and wages, I can then assess the degree of monopsony power of the firm in my data.

The different role that wages play in my model, compared with their role in perfectly competitive models such as GW, is critical for my results. Under perfect competition among identical firms, the wage paid by a firm reflects a worker's value to the firm. Under Bertrand competition among heterogeneous firms, the wage reflects a worker's value to the firm's competitors. Hence, wages paid by the firm in my data provide direct information about the technologies of other firms in the labor market. As a result, certain interpretable reduced-form parameters of other firms can be recovered just by estimating the wage process at this one firm. These parameters can then be used to assess the degree of transferability of unobserved ability and acquired human capital between firms.

The main intuition for the identification of the model is that performance data identify the process for learning independently of the process for human capital acquisition. Job transitions within the firm identify the process for output and human capital acquisition at the firm. In particular, differences in the hazard rate of promotion across tenures and levels identify the degree of task generality of the human capital acquired at a level or with overall tenure in the firm. Finally, wages identify the degree of generality of unobserved ability and acquired human capital across firms. I estimate the model by nonparametric maximum likelihood using eight years of observations on ten cohorts of managers entering into the firm between 1970 and 1979, imposing all of the theory's restrictions. The estimated model successfully captures the time profile of job-to-job transitions within the firm and separations from the firm, as well as the distribution of wages and performance at the main job levels in each tenure.

The estimates of the model's parameters imply several key features of the process of information acquisition at the firm. First, initial uncertainty at the time of a manager's entry into the firm proves to be substantial: over half of the managers in my data have initial priors (that their ability is high rather than low) close to 0.5. Second, initial priors about ability are highly heterogeneous across managers, implying a significant dispersion of information at the time of hiring. Third, learning is gradual: more than 15 years of high performance are necessary for the average prior about a manager's ability being high to reach 0.9. By comparing wage growth in the model and in a counterfactual scenario where the updating of beliefs is prevented, I find that learning contributes to more than 25 percent of wage growth on the job over the first seven years of tenure. The remaining growth is essentially from human capital acquisition. Intuitively, learning leads managers with higher ability and acquired human capital to be more quickly promoted to higher levels at which they earn higher wages. Thus, without learning wages increase more slowly.

Interestingly, according to the estimates of the learning parameters, the success rate of a manager is largest at the intermediate and highest levels of the firm's job hierarchy, but the informativeness of performance is largest at the lowest level. Hence, when deciding on a manager's assignment, the firm in my data experiments: it must weigh the benefit of a high success rate against the benefit 
of information about ability. The firm's desire to gather information about ability leads managers to be assigned to the lowest level of the job hierarchy - at which managers are paid lower wages for a much longer period than in the case when experimentation is absent. For instance, without experimentation, by the fourth year of tenure managers would experience higher wage growth than their total estimated wage growth over seven years. During the first seven years at the firm, wage growth would be 20 percent higher if learning occurred without experimentation.

Since the process for learning is gradual, I estimate that persistent uncertainty about ability significantly reduces the pace of promotion to higher levels of the job hierarchy and hence the pace of wage growth. Absent such uncertainty, managers would be rapidly promoted to higher-level jobs, at which they would be paid higher wages. Thus, both experimentation and uncertainty are responsible for a substantial compression of wage growth at low tenures in the firm.

Finally, I find that the human capital acquired with overall tenure at the firm is highly transferable across the levels of the firm's hierarchy, unlike the human capital acquired at a level. Initial human capital, as captured by a manager's education and age at entry into the firm, proves to be highly general across firms. A comparison of the estimated output and wage processes also reveals that the firm enjoys a large degree of monopsony power.

The model shares four features with existing models of careers in firms. First, I follow Rosen (1982), Waldman (1984), and GW in allowing higher-ability workers to have a comparative advantage at higher-level jobs of a firm's hierarchy. Second, as in Jovanovic (1979), Harris and Holmström (1982), MacDonald (1982), Miller (1984), Farber and Gibbons (1996), Jovanovic and Nyarko (1997), and GW, firms and workers learn symmetrically about a fixed set of a worker's productive skills. In contrast to Jovanovic (1979), Miller (1984), and Flinn (1986), ability has a common component across jobs and firms. Third, workers can improve their productivity over time and acquire human capital that (unlike GW) can be task- and firm-specific to varying degrees. Fourth, output is linearly separable across workers. ${ }^{5}$

Learning about worker productivity in the labor market has been empirically investigated by Miller (1984), Flinn (1986), Berkovec and Stern (1991), Nagypál (2007), and Groes, Kircher, and Manovskii (2010). Using a sample of executives from a French state-owned firm, Chiappori, Salanié and Valentin (1999) provide evidence of learning and downward wage rigidity in firms. Building on the approach of Gibbons et al. (2005), who study sectoral and inter-industry wage differentials, Lluis (2005) and Hunnes (2012) assess the importance of comparative advantage and learning for worker mobility within firms and across occupations, respectively. For evidence of the presence of learning in the BGH data, based on a perfectly competitive model without job assignment, see Khan and Lange (2011). None of these papers on careers recover primitive parameters of uncertainty and learning at a firm's jobs or assess the contribution of learning and human capital to wage growth.

\footnotetext{
${ }^{5}$ For the impact of complementarity in production among workers on the assignment of workers to tasks or teams, see Kremer (1993), Kremer and Maskin (1996), Davis (1997), and Ferrall (1997, 2009).
} 


\section{A Simple Model of Careers}

I start with a simplified model to develop intuition and then turn to the general model I estimate. See the Appendix and the online Supplementary Appendix for all omitted details.

Environment. A finite number of firms compete for workers over an infinite horizon with discrete dates $t \geq 1$. Firms produce a homogeneous output good, which they sell in a perfectly competitive market at a price normalized to one. Workers enter the labor market in period 1, so $t$ also represents the worker's experience. Workers are one of two types, $\theta \in\{\alpha, \beta\}$, where $\alpha$ is denoted high ability. Firms and workers share a common initial prior belief $p_{1}$ that a worker is of high ability. Both firms and workers discount the future by the factor $\delta \in(0,1)$. Each firm's technology is constant returns to scale in the only input to production, labor, with workers perfectly substitutable, and consists of $K^{f}$ tasks or jobs.

When a worker with human capital $h_{t}$ is assigned to job $k$ of firm $f$, output can take one of two values: high, $y_{f H k}\left(h_{t}\right)$, or low, $y_{f L k}\left(h_{t}\right)$. Realized output is observed by all firms and workers. (For analyses that relax this assumption, see Waldman (1984, 1990), Greenwald (1986), Ricart i Costa (1988), Bernhardt and Scoones (1993), Bernhardt (1995), and Waldman (1996). ${ }^{6}$ ) The probability that output is high depends on the worker's type, $\theta$, as well as $k$ and $f$. Denote by $\alpha_{f k}$ the probability a high ability worker produces high output and by $\beta_{f k}$ the probability a low ability worker produces high output at job $k$ of firm $f$. The type indices $\alpha=\left\{\alpha_{f k}\right\}$ and $\beta=\left\{\beta_{f k}\right\}$ are, thus, vectors of probabilities of high output for each type. Overall, each job is characterized by the four-tuple $\left\{y_{f H k}\left(h_{t}\right), y_{f L k}\left(h_{t}\right), \alpha_{f k}, \beta_{f k}\right\}$. Note that human capital, $h_{t}$, affects the magnitude of the output that a worker produces but has no impact on $\alpha_{f k}$ or $\beta_{f k}$. Thus, human capital has no effect on the updating rule of beliefs about a worker's ability. This assumption will allow me to empirically distinguish learning about ability from on-the-job human capital acquisition.

Since unobserved ability is a permanent characteristic of workers, it affects the quality of the match of a worker to all jobs and firms. Thus, learning is correlated across jobs and firms. ${ }^{7}$ The productivity of a worker's ability, however, can differ across jobs and firms. At one extreme, when $\alpha_{f k}$ and $\beta_{f k}$ vary only across jobs, ability is job-specific but general across firms. At the other extreme, when $\alpha_{f k}$ and $\beta_{f k}$ vary only across firms, ability is firm-specific but general across jobs. The pattern of job- and firm-specificity of ability can be different for workers of high and low ability. Depending on the heterogeneity of job technologies across firms, different patterns and degrees of complementarity between ability and jobs are possible. (See Pastorino (2013) for examples.)

At the beginning of $t$ all firms and workers share a common prior $p_{t}$ that a worker is of ability $\alpha$. Let $\bar{y}_{f}\left(\alpha, h_{t}, k\right)=y_{f L k}\left(h_{t}\right)+\alpha_{f k}\left[y_{f H k}\left(h_{t}\right)-y_{f L k}\left(h_{t}\right)\right]$ denote the expected output of a worker of

\footnotetext{
${ }^{6}$ See DeVaro and Waldman (2012) for evidence of the potentially important signaling role of education in the BGH data.

${ }^{7}$ Relaxing the assumption of independent ability across jobs and firms, as in Jovanovic (1979), avoids the counterfactual prediction that workers change jobs within a firm or turn over only upon unsuccessful performance.
} 
ability $\alpha$ with human capital $h_{t}$ at job $k$ of firm $f ; \bar{y}_{f}\left(\beta, h_{t}, k\right)$ is similarly defined for a worker of ability $\beta$. Given $p_{t}$, expected output, averaged over the two worker types, is given by

$$
y_{f}\left(p_{t}, h_{t}, k\right) \equiv \bar{y}_{f}\left(\beta, h_{t}, k\right)+\left[\bar{y}_{f}\left(\alpha, h_{t}, k\right)-\bar{y}_{f}\left(\beta, h_{t}, k\right)\right] p_{t}=b_{f k t}+c_{f k t} p_{t}
$$

where $b_{f k t}=\bar{y}_{f}\left(\beta, h_{t}, k\right)$ is the expected output of a low ability worker with human capital $h_{t}$ and $c_{f k t}=\bar{y}_{f}\left(\alpha, h_{t}, k\right)-\bar{y}_{f}\left(\beta, h_{t}, k\right)$ is the difference between the expected output of a high ability worker and that of a low ability worker with the same human capital, $h_{t}$. Note that $\bar{y}_{f}\left(\alpha, h_{t}, k\right)-$ $\bar{y}_{f}\left(\beta, h_{t}, k\right)=\left(\alpha_{f k}-\beta_{f k}\right)\left[y_{f H k}\left(h_{t}\right)-y_{f L k}\left(h_{t}\right)\right]$. I normalize to zero the outside option of a firm of not employing a worker. I assume that the outside option of a worker of not working in the market under consideration is a sufficiently low constant, $\bar{U}$, that the worker chooses to work in the market in each period. I normalize payoffs by $(1-\delta)$ so as to express them as per-period averages.

GW assumed perfect competition among firms with identical technologies. I relax this assumption by assuming a finite number of possible technologies exist, labeled by $\{A, B, C, \ldots\}$, and a zero cost to adopting technologies other than $A$. I assume that all technologies different from $A$ entail the same learning and human capital acquisition possibilities. (In the general model I relax these assumptions.) Free entry implies zero profits for any firm adopting a technology other than $A$. The positive cost of adoption of technology $A$ implies at most one firm will choose it. Otherwise, since ex-post competition among firms with technology $A$ would drive their profits to zero, such firms would make ex-ante negative profits by adopting technology $A$. The firm in the BGH data, referred to as firm $A$ or my firm, is interpreted as that one firm and is allowed to have incurred a strictly positive cost of adoption, that is, to be imperfectly competitive. ${ }^{8}$

After period $t$ production takes place, all firms and workers update beliefs about a worker's ability according to Bayes' rule, which leads to two possible values of $p_{t+1}$,

$$
P_{f H k}\left(p_{t}\right)=\frac{\alpha_{f k} p_{t}}{\alpha_{f k} p_{t}+\beta_{f k}\left(1-p_{t}\right)} \text { or } P_{f L k}\left(p_{t}\right)=\frac{\left(1-\alpha_{f k}\right) p_{t}}{\left(1-\alpha_{f k}\right) p_{t}+\left(1-\beta_{f k}\right)\left(1-p_{t}\right)} \text {, }
$$

depending, respectively, on whether high or low output is realized.

Since the probability of high output for a worker of either ability differs across jobs, the informativeness of a job, as measured by the dispersion in posterior beliefs after output is observed, and the speed of learning differ across jobs too. Then, the job that (conditional on $p_{t}$ and $h_{t}$ ) yields the highest current expected output in a period may not be the most informative. In determining an assignment for a worker, a firm trades off the worker's current expected output in a job against the value of the information revealed by output (in addition to the value of the human capital the worker accumulates with experience in that job). Similarly, when evaluating the prospect of

${ }^{8}$ That the output market in which all firms operate, including the one in my data, is perfectly competitive whereas the labor market where they hire their workers is imperfectly competitive is consistent with an island economy with a small number of firms on each island in which output is freely mobile across islands but labor is immobile. 
employment at different firms, a worker compares the wage he is currently offered to the value of the information (and, possibly, future human capital) acquired at the job he would perform. In this sense, both firms and worker face an experimentation problem when making their decisions.

Observe that if the sets of jobs $\left\{y_{f H k}\left(h_{t}\right), y_{f L k}\left(h_{t}\right), \alpha_{f k}, \beta_{f k}\right\}$ were identical across firms, then the labor market would be perfectly competitive, workers would be paid their expected output at the employing firm, and no turnover would occur (as long as there is an infinitesimal cost of switching firm). Differences in $\alpha_{f k}$ and $\beta_{f k}$ across jobs would still lead to experimentation within firms. If $\alpha_{f k}$ and $\beta_{f k}$ were also identical across jobs, then no experimentation would take place within firms either. This special case without experimentation and without turnover is the one studied by GW. ${ }^{9}$

The timing of events in a period $t$ is as follows. At the beginning of the period, all firms simultaneously submit offers to workers, which consist of a wage and a job assignment. (These offers can be interpreted as one-sided full commitment contracts that are renegotiated period by period: as shown below, these offers are sequentially optimal in that they maximize the expected presented discounted value of match surplus in each period. ${ }^{10}$ ) Next, each worker decides which offer to accept. The promised wage is then paid, production takes place, output at the accepted job at the employing firm is realized, and beliefs are updated based on observed output. (Since firms commit to the period offers they make, the timing of wage payments in a period is immaterial.) Without loss, I focus on the component game between all firms and one worker. In this game, the events in $t$ are given by $\left(\mathbf{w}_{t}, \mathbf{k}_{t}, \mathbf{d}_{t}, z_{t}\right)$, where $\left(\mathbf{w}_{t}, \mathbf{k}_{t}\right)=\left\{w_{f t}, k_{f t}\right\}_{f}$ denotes the vector of each firm $f$ 's wage and job offer; $\mathbf{d}_{t}=\left\{d_{f t}\right\}_{f}$, the vector of the worker's decisions to accept $\left(d_{f t}=1\right)$ or reject $\left(d_{f t}=0\right)$ each firm $f$ 's offer; and $z_{t}$, an indicator for whether realized output is high or low.

Equilibrium. I restrict attention to (robust) Markov perfect equilibria for which the state variable at the beginning of any period $t$ is $s_{t}=\left(p_{t}, h_{t}\right)$, which consists of the worker's prior, $p_{t}$, and acquired human capital, $h_{t}$. This is the state that firms face at the time they make their job and wage offers. The state for the worker consists of $s_{t}$ and the current vector of offers, $\left(\mathbf{w}_{t}, \mathbf{k}_{t}\right)$. An equilibrium consists of offer strategies $w_{f t}=w_{f}\left(s_{t}\right)$ and $k_{f t}=k_{f}\left(s_{t}\right)$ for each firm $f \in\{1, \ldots, \mathbb{N}\}$, an acceptance strategy $\mathbf{d}_{t}=\mathbf{d}\left(s_{t}, \mathbf{w}_{t}, \mathbf{k}_{t}\right)$ for the worker with typical element $d_{f t}=d_{f}\left(s_{t}, \mathbf{w}_{t}, \mathbf{k}_{t}\right), f \in\{1, \ldots, \mathbb{N}\}$, and belief updating rules $P_{f H k}\left(p_{t}\right)$ and $P_{f L k}\left(p_{t}\right)$ for all $f$ and $k \in K^{f}$ such that in each period: all firms maximize the expected present discounted value of profits, the worker maximizes the expected present discounted value of wages, non-employing firms are indifferent between employing and not employing the worker at the job that maximizes their expected present discounted value of profits, and beliefs are updated as in $(2) .{ }^{11}$

\footnotetext{
${ }^{9}$ See Ghosh (2007) for a model of learning, human capital acquisition, and competition among homogeneous firms, in which turnover stems from disutility shocks to continuing employment with the same firm.

${ }^{10}$ In terms of contracting, the model is quite different but complementary to the work of Thomas and Worrall (1988, 2007). Their work focuses on the implications of risk-sharing for wages under full information rather than on the implications of competition for wages under two-sided incomplete information, that is, learning, as in my case. For example, in their limited commitment framework, if workers were risk neutral, as they are in my model, then equilibrium would imply static wage contracts very different from mine, which involve dynamic considerations.

${ }^{11}$ The robustness requirement of equilibrium is that losing firms make credible offers in that, if the worker deviated
} 
Denote the worker's value at state $s_{t}, V^{w}\left(s_{t}, \mathbf{w}_{t}\left(s_{t}\right), \mathbf{k}_{t}\left(s_{t}\right)\right)$, by $V^{w}\left(s_{t}\right)$ using the fact that in equilibrium the wage and job offers of all firms, $\mathbf{w}_{t}\left(s_{t}\right)$ and $\mathbf{k}_{t}\left(s_{t}\right)$, depend on $s_{t}$. Denote by $V^{A}=\Pi^{A}+V^{w}$ the match surplus value of firm $A$, which is the sum of the (expected present discounted) value of profits of firm $A$ and wages of the worker. Denote by $V^{A}\left(s_{t}, f\right)$ the match surplus value of firm $A$ when the worker accepts the offer of firm $f \in\{A, B, C, \ldots\}$ at state $s_{t}$ and by $f_{0 t}=f_{0}\left(s_{t}\right)$ the best competitor of firm $A$, which is the competitor of firm $A$ most preferred by the worker. When firm $A$ employs the worker, firm $f_{0 t}$ is the second-best firm, that is, the firm offering the second-highest value of wages. When firm $A$ does not employ the worker, firm $f_{0 t}$ is the best firm, that is, the employing firm.

When deciding whether to employ the worker and which job to assign the worker to, from Bertrand logic it follows that firm $A$ solves a pseudo-planning problem with value $V^{A}\left(s_{t}\right)$ given by

$$
\max \left\{\max _{k \in K^{A}}\left\{(1-\delta) y_{A}\left(s_{t}, k\right)+\delta E V^{A}\left(s_{t+1} \mid s_{t}, k\right)\right\}, \max _{f \neq A, k \in K^{f}}\left\{(1-\delta) y_{f}\left(s_{t}, k\right)+\delta E V^{A}\left(s_{t+1} \mid s_{t}, k\right)\right\}\right\}
$$

that is, $V^{A}\left(s_{t}\right)=\max \left\{V^{A}\left(s_{t}, A\right), V^{A}\left(s_{t}, f_{0 t}\right)\right\}$, since job assignment and turnover are frictionless. I will expand on the logic behind (3) in the context of the example in Section 1.1 and in the general model. Briefly, recall that payoffs are normalized by $(1-\delta)$ so as to be expressed as per-period averages. The first term of $(3), V^{A}\left(s_{t}, A\right)$, is the value to firm $A$ and the worker of employment at firm $A$ whereas the second term, $V^{A}\left(s_{t}, f_{0 t}\right)$, is the value to firm $A$ and the worker of employment at firm $f_{0 t}$ at state $s_{t}$. Firm $A$ employs the worker if doing so yields a higher match surplus value than the match surplus value generated when the worker is employed by firm $f_{0 t}$, associated with the information generated at firm $f_{0 t}$, which is of value to firm $A$ and the worker. Conditional on employing the worker, firm $A$ chooses the job that yields that highest match surplus value.

The wage that firm $A$ pays also follows from Bertrand logic. Denote by $k_{0 t}=k_{0}\left(s_{t}\right)$ the job offered by firm $f_{0 t}$, by $y_{f_{0 t}}\left(s_{t}, k_{0 t}\right)$ the worker's expected output at firm $f_{0 t}$, and by $V^{0}$ the match surplus value of firm $f_{0 t}$. In equilibrium, when the worker is employed by firm $A$, the worker must be indifferent between the offers by $A$ and $f_{0 t}$ whereas firm $f_{0 t}$, by the definition of equilibrium, is indifferent between employing the worker or not. These two observations imply that, when employed by firm $A$, the worker is paid his expected output at the second-best firm $f_{0 t}$ at its offered job, $k_{0 t}$, plus a compensating wage differential that reflects any difference in informativeness and prospect for human capital acquisition between jobs $k_{0 t}$ and $k_{A t}$. Formally, the worker's wage

\footnotetext{
from the equilibrium path and accepted any of their offers, these firms would not incur a loss. This refinement of Markov perfect equilibrium is analogous to trembling-hand perfection and similar to refinements used in the literature (Bergemann and Välimäki (1996) and Felli and Harris (1996, 2004)), even in standard static Bertrand games of price competition. In my framework this refinement implies uniqueness of equilibrium. Lifting this restriction would lead to an uninteresting multiplicity of (Markov perfect equilibrium) outcomes that, as just argued, would not be robust to small perturbations of equilibrium strategies. See the Supplementary Appendix.
} 
when employed by firm $A$ at job $k_{A t}$ is

$$
w_{A}\left(s_{t}, \varepsilon_{t}\right)=y_{f_{0 t}}\left(s_{t}, k_{0 t}\right)+\Psi\left(s_{t}, k_{A t}\right),
$$

where $\Psi\left(s_{t}, k_{A t}\right)=\delta\left[E V^{0}\left(s_{t+1} \mid s_{t}, k_{0 t}\right)-E V^{0}\left(s_{t+1} \mid s_{t}, k_{A t}\right)\right] /(1-\delta)$ is the compensating wage differential; see the general model for details. As in search models with competitive poaching like Bagger et al. (2011), competition implies that the worker is paid a varying fraction of the surplus value generated with the employing firm, unless the poacher has the same technology as the employing firm. In this case, the worker is paid his expected output at firm $A$ in each period, thus capturing the entire surplus of the match with firm $A$.

A non-trivial sharing rule of the surplus between firm $A$ and the worker emerges here endogenously both through the dependence of current wages on expected output at other firms, $y_{f_{0 t}}\left(s_{t}, k_{0 t}\right)$, and through $\Psi\left(s_{t}, k_{A t}\right)$. In particular, note that through $\Psi\left(s_{t}, k_{A t}\right)$ the worker extracts any difference in the continuation surplus of firm $f_{0 t}$ if the worker was employed by firm $f_{0 t}$ rather than firm $A$ in the current period. Importantly, all of this difference is priced in the current wage. Similarly, in Bagger et al. (2011), a worker captures, through a given bargaining weight, a fraction of the difference in continuation surplus between a continued match with the employing firm and a match with the best poacher. This difference affects the worker's present value of wages as well as current wage, through revisions of the contractual share of the output at the employing firm that the worker receives as wage. By construction, then, in Bagger et al. (2011) the worker can be paid at most his current output in a period. Here, on the contrary, the wage paid by firm $A$ can be smaller or larger than a worker's expected output at firm $A$, depending on the relative informativeness of job $k_{0 t}$ of firm $f_{0 t}$ and job $k_{A t}$ of firm $A$. In the following example, I illustrate these features of the model and its identification.

\subsection{An Example}

Suppose the market consists of firm $A$ and two firms of type $B$ and the time horizon is two periods. I begin with a simple setting without human capital acquisition in which firm $A$ has two jobs, referred to as $A 1$ and $A 2$, and each firm of type $B$ has only one job, referred to as $B 1$. This setting is sufficient to show that equilibrium implies a nondegenerate and imperfectly assortative distribution of workers to jobs and firms and naturally generates job-to-job mobility between firms in equilibrium, as well as wage increases (and possibly promotion) in response to good performance and wage decreases (and possibly demotion) in response to bad performance. In addition, in this setting wages paid by firm $A$ do not equal a worker's expected output at firm $A$ but the compensating wage differential is zero. A compensating differential arises when each firm $B$ has a second job or in the presence of human capital acquisition. See also the Supplementary Appendix.

For simplicity, assume that job $A 1$ is uninformative about ability $\left(\alpha_{A 1}=\beta_{A 1}\right)$, job $A 2$ is 
moderately informative $\left(\alpha_{A 2}=\alpha>\beta_{A 2}=\beta\right.$ and $\left.\alpha, \beta \in(0,1)\right)$, and job $B 1$ is perfectly informative $\left(\alpha_{B 1}=1\right.$ and $\left.\beta_{B 1}=0\right)$. Then, the only nontrivial updating rules are for job $A 2$. I simplify the notation for them from $P_{A H 2}(p)$ and $P_{A L 2}(p)$ to $P_{H}(p)$ and $P_{L}(p)$. The initial prior belief that a worker is of high ability is simply $p$. The worker's expected output at firm $f \in\{A, B\}$ in job $k$ in any period is then $y_{f}(p, k)=b_{f k}+c_{f k} p$. As depicted in Figure 1, I assume that ability and jobs are complementary: a worker known to be of low ability is best suited to $A 1$, next-best suited to $A 2$, and least suited to $B 1$ whereas a worker known to be of high ability is best suited to $B 1$, nextbest suited to $A 2$, and least suited to $A 1$. Hence, in the absence of uncertainty, matching would be perfectly assortative with high ability workers employed by firms $B$ and low ability workers employed by firm $A$ at job $A 1$.

Job Assignment. In period 2, job assignment is a static decision. Define $p_{A 2}^{s}$ as the static prior cutoff between jobs $A 1$ and $A 2$, which satisfies $y_{A}\left(p_{A 2}^{s}, 1\right)=y_{A}\left(p_{A 2}^{s}, 2\right)$. Similarly, define $p_{B 1}^{s}$ as the static cutoff prior between jobs $A 2$ and $B 1$, which satisfies $y_{A}\left(p_{B 1}^{s}, 2\right)=y_{B}\left(p_{B 1}^{s}, 1\right)$. Due to Bertrand competition, type $B$ firms behave as perfect competitors and pay a worker his expected output in each period. The match surplus value of firm $A$ in period 2 is then $V_{2}^{A}(p)=$ $\max \left\{\max _{k} y_{A}(p, k), y_{B}(p, 1)\right\}$. That is, when firm $A$ employs the worker, $V_{2}^{A}$ is simply the worker's expected output at firm $A$. When a firm of type $B$ employs the worker, $V_{2}^{A}$ is the worker's wage (firm $A$ 's profit is zero), which equals the worker's expected output at a firm of type $B$. By complementarity between ability and jobs, it follows that in equilibrium job $A 1$ is assigned at $p<p_{A 2}^{s}$, job $A 2$ at $p \in\left[p_{A 2}^{s}, p_{B 1}^{s}\right)$, and job $B 1$ at $p \geq p_{B 1}^{s}$. This is also the policy function solution to firm $A$ 's match surplus value problem.

In period 1 the match surplus value of firm $A$ is $V_{1}^{A}(p)=\max \left\{\max _{k} V_{1}^{A}(p, k), V_{1}^{A}(p, B)\right\}$, where

$$
V_{1}^{A}(p, k)=(1-\delta) y_{A}(p, k)+\delta\left\{r_{A k}(p) V_{2}^{A}\left(P_{A H k}(p)\right)+\left[1-r_{A k}(p)\right] V_{2}^{A}\left(P_{A L k}(p)\right)\right\}
$$

$k=1,2$, and $r_{A k}(p)=\alpha_{A k} p+\beta_{A k}(1-p) . V_{1}^{A}(p, B)$ is similarly defined: in this case the one-period match surplus value is given by $y_{B}(p, 1)$ and the probability of success by $r_{B 1}(p)=p$. Now, since job $A 2$ is more informative than job $A 1$, the cutoff prior $p_{A 2}^{d}$ at which firm $A$ is indifferent between assigning the worker to jobs $A 1$ and $A 2$ in the first period satisfies

$$
p_{A 2}^{d}<p_{A 2}^{s}
$$

Hence, in equilibrium the worker is assigned to job $A 2$ in the first period at lower priors than the lowest priors at which he is assigned to $A 2$ in the second period. In particular, at priors between $p_{A 2}^{d}$ and $p_{A 2}^{s}$ a worker is assigned to job $A 2$ even if his output would be higher at job $A 1$. In this sense, firm $A$ and the worker experiment: they sacrifice expected output and wages in the current period in order to acquire information for the benefit of output and wages in the next period. Likewise, since job $B 1$ is more informative than $A 2$, the cutoff prior $p_{B 1}^{d}$ at which firm $A$ is indifferent between 
assigning the worker to job $A 2$ and losing him to a firm of type $B$ in the first period satisfies

$$
p_{B 1}^{d}<p_{B 1}^{s} .
$$

So, in equilibrium job $A 1$ is assigned at $p<p_{A 2}^{d}$, job $A 2$ at $p \in\left[p_{A 2}^{d}, p_{B 1}^{d}\right)$, and job $B 1$ at $p \geq p_{B 1}^{d}$. This is also the policy function solution to firm $A$ 's match surplus value problem in the first period.

Consider workers who start in job $A 2$, that is, with priors above $p_{A 2}^{d}$ but below $p_{B 1}^{d}$. For concreteness, I focus on the following outcomes depicted in Figure 2: a worker with prior $p_{A 2}^{d}$ stays in job $A 2$ after a success, a worker with the highest initial prior at job $A 2$ (just below $p_{B 1}^{d}$ ) stays in $A 2$ after a failure, and a worker with the lowest initial prior at job $B 1, p_{B 1}^{d}$, stays in $B 1$ after a success. Let $P_{H}^{-1}$ and $P_{L}^{-1}$ denote the inverse functions of $P_{H}$ and $P_{L}$, respectively. Panel A in Figure 3 illustrates the outcome after a success under these assumptions. Workers with $p$ below $P_{H}^{-1}\left(p_{B 1}^{s}\right)$ stay in job $A 2$ since $P_{H}(p)<p_{B 1}^{s}$ and workers with $p$ above it move to a firm of type $B$ since $P_{H}(p) \geq p_{B 1}^{s}$. Panel $\mathrm{B}$ in Figure 3 illustrates the outcome after a failure. Workers with $p$ below $P_{L}^{-1}\left(p_{A 2}^{s}\right)$ are demoted to $A 1$ since $P_{L}(p)<p_{A 2}^{s}$ and workers with $p$ above it stay in job $A 2$.

Wages. In the second period, Bertrand competition implies that the wage paid by firm $A$ is the worker's expected output at a firm of type $B$. As discussed, each firm of type $B$ pays the worker his expected output in each period. Consider now the first period wage paid by firm $A$ to a worker employed at job $A 2$. These wages must yield a present value that makes the worker indifferent between working at firm $A$ and at a firm of type $B$. Based on the outcomes just characterized, after a success at job $A 2$, depending on the prior in period 1 , the worker is either retained at job $A 2$ or employed by a firm of type $B$. In both cases, he is paid $y_{B}\left(P_{H}(p), 1\right)$. After a failure at job $A 2$, the worker is either retained at job $A 2$ or demoted to job $A 1$. In both cases, he is paid $y_{B}\left(P_{L}(p), 1\right)$. Since expected output is affine in the prior and the mean of the posterior is the prior, the present value of wages for a worker initially in $A 2$ is then $(1-\delta) w_{A}(p)+\delta y_{B}(p, 1)$. As for the present value of wages for a worker initially employed by a firm of type $B$, note first that such a worker is paid in the first period $y_{B}(p, 1)$. After a success at job $B 1$, the worker is retained and paid $y_{B}(1,1)$. After a failure at job $B 1$, the worker moves to job $A 1$ of firm $A$ and is paid $y_{B}(0,1)$. So, the present value of wages for workers initially in $B 1$ is $y_{B}(p, 1)$. Equating these two present values of wages yields $w_{A}(p)=y_{B}(p, 1)<\max _{k} y_{A}(p, k)$ since $p<p_{B 1}^{s}$. Consider next the compensating wage differential. Since $E V_{2}^{B}$ equals $y_{B}(p, 1)$ regardless of the worker's assignment in the first period, in this case

$$
\Psi(p, A 2) \equiv \frac{\delta}{1-\delta}\left[E V_{2}^{B}\left(p^{\prime} \mid p, k_{B 1}\right)-E V_{2}^{B}\left(p^{\prime} \mid p, k_{A 2}\right)\right]=0 .
$$

Intuitively, the extra information $B 1$ provides relative to $A 2$ has no impact on the future output of a firm of type $B$ when such a firm has only one job.

Wages and Compensating Differential. To see how a nonzero compensating differential arises, 
suppose now that the type $B$ firms have two jobs and their best assignment is job $B 1$ at $p=0$ and job $B 2$ at $p=1$. Let $B 1$ and $B 2$ be perfectly informative. Denote by $p_{B 2}$ the static and dynamic cutoff prior such that $y_{B}(p, 1)=y_{B}(p, 2)$. Suppose that $B 1$ is dominated by job $A 1$ at all priors and that $p_{B 2}<p_{A 2}^{d}$. Then, for workers with priors between $p_{A 2}^{d}$ and $p_{B 1}^{d}$ to be indifferent between working at job $A 2$ at firm $A$ and at job $B 2$ at a firm of type $B$, it can be shown that the first period wage must be $w_{A}(p)=y_{B}(p, 2)+\Psi(p, A 2)$ with

$$
\Psi(p, A 2)=\frac{\delta}{1-\delta}\left\{p y_{B}(1,2)+(1-p) y_{B}(0,1)-\left[r_{A 2}(p) y_{B}\left(P_{H}(p), 2\right)+\left(1-r_{A 2}(p)\right) y_{B}\left(P_{L}(p), 1\right)\right]\right\}>0
$$

since $V_{2}^{B}$ is convex in $p$ and posterior beliefs reached when job $B 2$ is assigned are a mean-preserving spread of the posteriors reached when job $A 2$ is assigned. In this case, the extra information $B 2$ provides relative to $A 2$ has an impact on the future output of a firm of type $B$. Its value is priced in the worker's current wage.

Wages vs. Expected Output. Even when the compensating wage differential is zero, in general the wages paid by firm $A$ are different from a worker's expected output. As shown, a worker employed by firm $A$ at job $A 2$ in the first period is paid $w_{A}(p)=y_{B}(p, 1)<\max _{k} y_{A}(p, k)$ since $p<p_{B 1}^{s}$ when a firm of type $B$ has only one job. To see how wages larger than expected output arise, suppose now that job $A 2$ is more informative than job $B 1$ and again that each firm of type $B$ has only one job. By logic analogous to the above, it follows $p_{B 1}^{s}<p_{B 1}^{d}$ due to the informational advantage of job $A 2$ over job $B 1$. Thus, for workers with priors above $p_{B 1}^{s}$ and below $p_{B 1}^{d}$, the wage in the first period is $w_{A}(p)=y_{B}(p, 1)>\max _{k} y_{A}(p, k)=y_{A}(p, 2)$ since $p>p_{B 1}^{s}$. In this case, firm $A$ pays the worker more than his expected output in order to acquire information about his ability.

Human Capital. Suppose workers can acquire human capital when employed. In this case, the compensating wage differential need not be zero even if a firm of type $B$ has only one job as long as the accumulation process differs across firm types. To see this, suppose human capital acquisition takes the form $b_{f k t}=b_{f k}+h_{f k}\left(k_{t-1}\right) \cdot(t-1)$ and $c_{f k t}=c_{f k}+h_{f k}\left(k_{t-1}\right) \cdot(t-1)$; this formulation is similar to the one I use when estimating the model. Then, expected output depends on the job the worker has been assigned to in the previous period, $k_{t-1}$, and the worker's experience in the labor market, $t-1$. The extent to which human capital is transferable across jobs and firms depends on $h_{f k}\left(k_{t-1}\right)$. For workers with $p$ in $\left[P_{H}^{-1}\left(p_{B 1}^{s}\right), P_{L}^{-1}\left(p_{A 2}^{s}\right)\right)$, it can be shown the first period wage is

$$
w_{A}(p)=y_{B}(p, 1)+\frac{\delta}{1-\delta}(\underbrace{b_{B 1}+h_{B 1}(B 1)+\left[c_{B 1}+h_{B 1}(B 1)\right] p}_{E V_{2}^{B}\left(\cdot \mid p, k_{B 1}\right)}-\{\underbrace{b_{B 1}+h_{B 1}(A 2)+\left[c_{B 1}+h_{B 1}(A 2)\right] p}_{E V_{2}^{B}\left(\cdot \mid p, k_{A 2}\right)}\})
$$

where $\Psi(p, A 2)>0$ if, and only if, at type $B$ firms, the human capital acquired at job $A 2$ of firm $A$ is less valuable than the human capital acquired at job $B 1$, that is, $h_{B 1}(B 1)>h_{B 1}(A 2)$. Thus, the wage compensates the worker for forgoing the relatively more valuable human capital at firm 
$B$. It is also possible that a worker is never demoted after low performance, as commonly observed in the data: the increase in human capital of value at jobs $A 2$ and $B 1$ can offset the adverse belief revision triggered by low output.

Identification. Consider the more general case in which both jobs $A 1$ and $A 2$ are informative about ability and human capital acquisition is present. The main intuition for the separate identification of the processes for learning and human capital acquisition at firm $A$ is simple. In the model human capital accrues deterministically with experience, as in a standard learning-by-doing setup, and it only affects a worker's output at the job $k$ of each firm $f, y_{f H k}\left(h_{t}\right)$ or $y_{f L k}\left(h_{t}\right)$. In particular, human capital has no impact on belief updating, that is, on the parameters $\alpha_{f k}$ and $\beta_{f k}$. The Supplementary Appendix shows that in this framework repeated performance information at each job of firm $A$ is sufficient to identify $p_{1}$ and $\left\{\alpha_{A k}, \beta_{A k}\right\}_{k=1}^{2}$. To see why, suppose that $p_{1}$ is known. Consider individuals assigned to job $A 1$ in both periods and equate the sample proportions of individuals with a success at the end of period 1 , denoted by $m_{A 11}^{o}$, and with another success at the end of period 2, denoted by $m_{A 12 \mid H 1}^{o}$, to their theoretical counterparts,

$$
\left\{\begin{array}{l}
\alpha_{A 1} p_{1}+\beta_{A 1}\left(1-p_{1}\right)=m_{A 11}^{o} \\
\frac{\alpha_{A 1}^{2} p_{1}}{\alpha_{A 1} p_{1}+\beta_{A 1}\left(1-p_{1}\right)}+\frac{\beta_{A 1}^{2}\left(1-p_{1}\right)}{\alpha_{A 1} p_{1}+\beta_{A 1}\left(1-p_{1}\right)}=m_{A 12 \mid H 1}^{o}
\end{array}\right.
$$

by using the definition of $P_{A H 1}\left(p_{1}\right)$. This system has a unique solution for $\alpha_{1}$ and $\beta_{1}$, so $\alpha_{1}$ and $\beta_{1}$ are identified. Three periods of repeated observations on performance at job $A 1$ are sufficient to identify $p_{1}$ as well. Similarly, two periods of observations at $A 2$ identify $\alpha_{A 2}$ and $\beta_{A 2}$. As shown in the Supplementary Appendix, an analogous argument holds in the presence of classification error.

The output and human capital processes at firm $A$ are identified by the argument in Magnac and Thesmar (2002) when $\delta$ is known. Under standard assumptions, Magnac and Thesmar prove that dynamic discrete choice models are nonparametrically identified up to the continuation value from one alternative, $K$. Note that the problem of firm $A$ consists of the choice among job $A 1, A 2$, and 'employment at a firm of type $B$ '. Hence, by interpreting alternative $K$ as employment at a firm $B$ and parameterizing $E V_{t}^{A}\left(p_{t}, B\right)$, the differences between the parameters $b_{A k}, c_{A k}$, and $h_{A k}$ and the corresponding parameters at the second-best firm $B$ are identified. See the Supplementary Appendix for details.

\section{A General Model of Careers}

Now assume that all firms operate exclusive technologies and, thus, are imperfectly competitive. In this setting I also introduce productivity shocks, realized at the beginning of each period, and separation shocks, realized (if at all) at the end of a period. This is the model I estimate.

Output in period $t$ is now either $y_{f H k}\left(h_{t}\right)+\varepsilon_{f k t}$ or $y_{f L k}\left(h_{t}\right)+\varepsilon_{f k t}$, where $\varepsilon_{f k t}$ is a mean-zero type 
I extreme value productivity shock with c.d.f. $G$, which captures idiosyncratic features of the match between a worker and a job, and is independent across jobs, time, and of the worker's ability. The expected output of a worker with prior $p_{t}$ and human capital $h_{t}$ at job $k$ of firm $f$ after productivity shocks are realized, but before $y_{f H k}\left(h_{t}\right)$ or $y_{f L k}\left(h_{t}\right)$ is realized, is then $y_{f}\left(p_{t}, h_{t}, k\right)+\varepsilon_{f k t}$.

Here the ability-dependent component of output, $y_{f H k}\left(h_{t}\right)$ or $y_{f L k}\left(h_{t}\right)$, that is, the worker's performance, is modelled as discrete because it is assumed to be measured in the data by a worker's performance rating, which is essentially 'high' or 'low'. I maintain the assumption of only two types of workers, common in the literature, for its convenience and flexibility. It implies that the probability that a worker is of high ability is a sufficient statistic for beliefs and, thus, conveniently reduces the computational burden of maximum likelihood estimation. Together with the assumption of two values for performance, it also parsimoniously allows for greater flexibility in the process for beliefs compared to, say, a normal prior-signal learning structure. In the Bernoulli case, unlike in the normal prior-signal case, the variance of posterior beliefs need not decline deterministically in $t$. Lastly, note that without productivity shocks, employment and job assignment policies, being Markovian, would be deterministic functions of beliefs. Thus, given that worker types and performance ratings are discrete, productivity shocks guarantee a nondegenerate likelihood function.

To allow for separations unrelated to ability or performance, I assume that after production a worker leaves the market with probability $1-\eta_{f k}\left(h_{t}\right)$. Hence, a job is now characterized by the six-tuple $\left\{y_{f H k}\left(h_{t}\right), y_{f L k}\left(h_{t}\right), \alpha_{f k}, \beta_{f k}, \varepsilon_{f k t}, \eta_{f k}\left(h_{t}\right)\right\} .{ }^{12}$ The state that firms face at the time they make their job and wage offers consists of $s_{t}$ and the vector of productivity shocks realized at the jobs of each firm, $\varepsilon_{t}$. The state that the worker faces when choosing which offer to accept consists of $s_{t}$, the productivity shocks of all firms, $\boldsymbol{\varepsilon}_{t}$, and the current vector of offers of all firms, $\left(\mathbf{w}_{t}, \mathbf{k}_{t}\right)$.

As before, by combining the optimality conditions of firm $A$ and the worker, it is possible to show that the (best-response) problem determining the job choice of firm $A$ and the set of states at which firm $A$ employs the worker corresponds to the problem of maximizing the sum of the (expected present discounted) values of firm $A$ 's profits and the worker's wages - both when the worker is employed by firm $A$ and when the worker is employed by another firm in equilibrium. In particular, in equilibrium the value of this problem is the match surplus value of firm $A$, which solves the Bellman equation in the next proposition. (For omitted proofs and details, see the Appendix and Supplementary Appendix.) From now on, I will denote the worker's value at state $\left(s_{t}, \boldsymbol{\varepsilon}_{t}\right)$ compactly by $V^{w}\left(s_{t}, \boldsymbol{\varepsilon}_{t}\right)$ rather than $V^{w}\left(s_{t}, \boldsymbol{\varepsilon}_{t}, \mathbf{w}_{t}\left(s_{t}, \boldsymbol{\varepsilon}_{t}\right), \mathbf{k}_{t}\left(s_{t}, \boldsymbol{\varepsilon}_{t}\right)\right)$ and the best competitor of firm $A$ at state $\left(s_{t}, \varepsilon_{t}\right)$ by $f_{0 t}=f_{0}\left(s_{t}, \varepsilon_{t}\right)$.

\footnotetext{
${ }^{12}$ As long as new workers enter into the market each period, the market will always be populated by workers. Given the assumed separability of workers in production, this aspect is irrelevant for my analysis.
} 
Proposition 1. Firm A's match surplus value, $V^{A}\left(s_{t}, \boldsymbol{\varepsilon}_{t}\right)=\max \left\{V^{A}\left(s_{t}, \boldsymbol{\varepsilon}_{t}, A\right), V^{A}\left(s_{t}, \boldsymbol{\varepsilon}_{t}, f_{0 t}\right)\right\}$, is

$$
\max \left\{\max _{k \in K^{A}}\left\{(1-\delta)\left[y_{A}\left(s_{t}, k\right)+\varepsilon_{A k t}\right]+\delta \eta_{A k}\left(h_{t}\right) \int_{\varepsilon_{t+1}} E V^{A}\left(s_{t+1}, \varepsilon_{t+1} \mid s_{t}, k\right) d G\right\}, V^{A}\left(s_{t}, \varepsilon_{t}, f_{0 t}\right)\right\} .
$$

To interpret (7), consider first the inner maximization problem, whose value is $V^{A}\left(s_{t}, \varepsilon_{t}, A\right)$. This problem characterizes the job choice of firm $A$ if it employs the worker at state $\left(s_{t}, \boldsymbol{\varepsilon}_{t}\right)$. If firm $A$ employs the worker, then the current period value, $y_{A}\left(s_{t}, k\right)+\varepsilon_{A k t}$, consists of the sum of firm $A$ 's current expected profits at the chosen job $k, y_{A}\left(s_{t}, k\right)+\varepsilon_{A k t}-w$, and the worker's wage, $w$. The future value, $E V^{A}$, is the sum of the continuation value of firm $A$ 's profits and of the worker's wages, conditional on the assignment of job $k$. This inner maximization problem implies that when firm $A$ employs the worker, it assigns the worker to the job that maximizes match surplus. This result follows immediately from three features of the model: in equilibrium the offer of the employing firm makes the worker indifferent between accepting its offer and that of firm $f_{0 t}$, the firm's and the worker's one-period payoffs are linear in the worker's wage, and there are no frictions in job assignment or turnover.

Consider next the outer maximization problem in (7). The term $V^{A}\left(s_{t}, \varepsilon_{t}, f_{0 t}\right)$ is firm $A$ 's match surplus value when the worker is employed by a firm different from $A$ - both at equilibrium states at which firm $A$ employs the worker and at states at which firm $A$ does not employ the worker. This firm is $f_{0 t}$ by definition: in equilibrium when firm $A$ employs the worker, $f_{0 t}$ is the best competitor, when firm $A$ does not employ the worker, firm $f_{0 t}$ is the employing firm. Hence, $V^{A}\left(s_{t}, \boldsymbol{\varepsilon}_{t}, f_{0 t}\right)$ is the sum of the current payoff $w_{0}\left(s_{t}, \boldsymbol{\varepsilon}_{t}\right)$, which is the wage offered by firm $f_{0 t}$ (firm $A$ 's current profit is zero), weighted by $1-\delta$, and the future value $E V^{A}\left(\cdot \mid s_{t}, k_{0 t}\right)$, weighted by $\delta$, conditional on the assignment of job $k_{0 t}=k_{0}\left(s_{t}, \boldsymbol{\varepsilon}_{t}\right)$ of firm $f_{0 t}$ with associated probability of exogenous separation $1-\eta_{0 t}\left(h_{t}\right)$. This outer maximization problem is an immediate implication of firm and worker optimality. When the worker is employed by firm $A$, both firm $A$ and the worker prefer this outcome to the one in which the worker is employed by the best competitor of firm $A$, taking into account the value of the information and human capital that would be acquired if the worker was employed by firm $f_{0 t}$. When the worker is employed by firm $f_{0 t}$, both firm $A$ and the worker prefer employment at firm $f_{0 t}$ to employment at firm $A$. By summing firm $A$ 's and the worker's values in each case, it follows that $V^{A}\left(s_{t}, \varepsilon_{t}\right)$ must achieve the maximum between $V^{A}\left(s_{t}, \varepsilon_{t}, A\right)$ and $V^{A}\left(s_{t}, \boldsymbol{\varepsilon}_{t}, f_{0 t}\right)$.

Proposition 1 has two crucial implications. First, the match surplus value problem determines not only the job chosen by firm $A$ but also the set of states at which firm $A$ employs the worker, that is, the states $\left(s_{t}, \varepsilon_{t}\right)$ at which $V^{A}\left(s_{t}, \varepsilon_{t}, A\right)$ is larger than $V^{A}\left(s_{t}, \varepsilon_{t}, f_{0 t}\right)$. Second, the match surplus value problem is analogous to a pseudo-planning problem among $K^{A}+1$ alternatives. The difference, compared to a standard single-agent dynamic discrete choice problem, is that here firm $A$ 
has monopsony power and is competing against other firms. Hence, the alternative to employment at one of the $K^{A}$ jobs of firm $A$ is determined by equilibrium and corresponds to employment at a firm different from $A$.

Proposition 1 applies to any market structure. In estimation, due to data limitations, I consider three possible market structures: perfect competition, duopoly, and an oligopoly in which all competitors of firm $A$ face no cost of technology adoption and their technologies entail the same prospect for learning, human capital acquisition, and exogenous separation. This type of oligopoly is similar to the case of a dominant firm and a competitive fringe. These three market structures are naturally nested by (7). ${ }^{13}$ The perfectly competitive case is a special case in which all firms have identical technologies and equilibrium is efficient. In this case, the job assignment problem of firm $A$ has value $V^{A}=V^{*}$, where $V^{*}$ is the value function of the planner's problem, and $V^{A}\left(s_{t}, \varepsilon_{t}, f_{0 t}\right)=V^{A}\left(s_{t}, \varepsilon_{t}, A\right)$, since firms have identical technologies. When the labor market is a duopoly between firms $A$ and $B$, then $V^{A}\left(s_{t}, \varepsilon_{t}\right)=V^{A}\left(s_{t}, \varepsilon_{t}, A\right)$, where $V^{A}\left(s_{t}, \varepsilon_{t}, A\right)$ is the value of the inner maximization problem in (7). This result is due to the equilibrium 'double indifference' of the worker between the two firms' offers and of the non-employing firm between employing and not employing the worker.

When the labor market is an oligopoly as described, it can be shown that

$$
V^{A}\left(s_{t}, \boldsymbol{\varepsilon}_{t}, f_{0 t}\right)=\ln \sum_{f \neq A, k \in K^{f}} \exp \left\{(1-\delta) y_{f}\left(s_{t}, k\right)+\delta \eta_{f k}\left(h_{t}\right) \int_{\varepsilon_{t+1}} E V^{A}\left(\cdot \mid s_{t}, k\right) d G\right\}+(1-\delta) \varepsilon_{0 t}
$$

where $\varepsilon_{0 t}$ is the productivity shock realized at the job offered by the best competitor of firm $A$. Note that $(8)$ is akin to a value function for a standard single-agent decision problem involving the choice among $\cup_{f \neq A} K^{f}$ alternatives. See the Appendix and the Supplementary Appendix. In the duopoly and oligopoly cases, however, equilibrium assignment does not necessarily solve the planner's problem: firms do not take into account their competitors' profits when choosing their jobs. Further, wages paid by firm $A$ do not equal expected output at firm $A$. Yet, in all these cases, the states at which firm $A$ employs the worker and the job it chooses can be determined by solving the match surplus value problem in (7). In particular, the value functions of Proposition 1 provide the first set of estimating equations. The next result derives the expression for paid wages, which provides the second main estimating equation.

Proposition 2. The worker's equilibrium wage when employed by firm $A$ at job $k_{A t}$ is

$$
w_{A}\left(s_{t}, \varepsilon_{t}\right)=y_{f_{0 t}}\left(s_{t}, k_{0 t}\right)+\Psi\left(s_{t}, k_{A t}\right)+\varepsilon_{0 t}
$$

where $\Psi\left(s_{t}, k_{A t}\right)=\frac{\delta}{1-\delta} \int_{\varepsilon_{t+1}}\left[\eta_{0}\left(h_{t}\right) E V^{0}\left(\cdot \mid s_{t}, k_{0 t}\right)-\eta_{A k_{A t}}\left(h_{t}\right) E V^{0}\left(\cdot \mid s_{t}, k_{A t}\right)\right] d G$.

\footnotetext{
${ }^{13}$ For all other market structures, the formulation of the employment and job assignment problem I use in estimation is an approximation of the exact one. See the Appendix.
} 
See the Supplementary Appendix for the proof. By Proposition 2, the wage paid by firm $A$ is the sum of the current expected output of the worker at the second-best firm $f_{0 t}, y_{f_{0 t}}\left(s_{t}, k_{0 t}\right)+$ $\varepsilon_{0 t}$, and the compensating wage differential term $\Psi\left(s_{t}, k_{A t}\right)$. This term compensates the worker for the three dimensions along which the job offered by firm $A$ differs from the one offered by the second-best firm $f_{0 t}$. Specifically, jobs at firms $A$ and $f_{0 t}$ may provide different amounts of information about the worker's ability, offer different possibilities of human capital acquisition, and imply different probabilities of exogenous separation. All these dimensions affect the present value of wages from period $t+1$ on and, due to competition, are reflected in the current paid wage. This compensating differential would be zero if firms $A$ and $f_{0 t}$ provided the worker with identical prospects for information, human capital acquisition, and exogenous separation.

Recall that $\bar{U}$ is the worker's outside option. In equilibrium, when employed by firm $A$, the worker receives in present value terms the share $\Lambda=\left(V^{w}-\bar{U}\right) /\left(V^{A}-\bar{U}\right)$ of the match surplus $V^{A}-\bar{U}$. Note that $\Lambda \in[0,1]$ since $\bar{U} \leq V^{w} \leq V^{A}$. From (9) and the definition of $V^{w}$ it follows

$$
V^{w}\left(s_{t}, \varepsilon_{t}\right)=V^{0}\left(s_{t}, \varepsilon_{t}\right)-\delta \eta_{A k_{A t}}\left(h_{t}\right) \int_{\varepsilon_{t+1}} E \Pi^{0}\left(s_{t+1} \mid s_{t}, k_{A t}\right) d G
$$

by simple algebra. Thus, as firm $f_{0 t}$ 's match surplus value $V^{0}$ varies relative to firm $A$ 's, so does the worker's share of firm $A$ 's match surplus. In particular, the worker extracts the entire surplus of the match with firm $A(\Lambda=1)$ only when the best outside offer is from a firm with the same technology as $A$. In this case, in fact, (on average over productivity shocks) $\Pi^{0}=\Pi^{A}=0$ and $V^{w}=V^{0}=V^{A}$.

The expression in (9) implies a flexible relation between a worker's wage and expected output at firm $A$. Suppose, for example, that the worker's expected output at the job offered by firm $f_{0 t}$ is lower than at firm $A$ 's job but that firm $f_{0 t}$ 's job implies learning, human capital, and separation prospects similar to firm $A$ 's job. Then, the compensating wage differential is (close to) zero and the worker is paid only a fraction of his expected output at firm $A: w_{A}\left(s_{t}, \varepsilon_{t}\right)<y_{A}\left(s_{t}, k\right)+\varepsilon_{A k t}$. By (9), the wage can also more than exhaust the worker's expected output at firm $A$, that is, $w_{A}\left(s_{t}, \boldsymbol{\varepsilon}_{t}\right) \geq y_{A}\left(s_{t}, k\right)+\varepsilon_{A k t}$, as shown in the example in Section 1.1. It can also occur if firm $A$ 's job allows the worker to acquire human capital highly valuable at both firms. In short, (9) provides an equilibrium foundation for a flexible wage determination rule that does not restrict the worker to be paid his expected output at the employing firm.

\section{Data}

The data, collected and first analyzed by BGH, are personnel records of all management employees of a medium-sized U.S. firm in a service industry, as of December 31 of each year between 1969 and 1988. I use information on a manager's year of entry, age, education, job level, (real) salary, and 
job performance rating.

BGH constructed the firm's hierarchy using managers' job titles and transitions across them. It consists of two distinct parts, Levels 1-4, which employ 97.6 percent of managers, and Levels 5-8. Level 8 is the highest title of Chairman-CEO. The average age of managers in the data is 39 years with a standard deviation of approximately 10 years, from a minimum of 20 to a maximum of 71. Their average number of years of education is 15 , with a standard deviation of approximately 2 years, from a minimum of 12 (high school degree) to a maximum of 23 (Ph.D.). Both age and education display little variation across cohorts. The composition of entrants across job titles does not change markedly over the years either, despite the increase in lower-level entry between 1976 and $1985 .^{14}$

Given the small number of individuals observed at Levels 3 and higher, in estimation I treat them as a single level. Level 1, Level 2, and this composite Level 3 correspond to jobs $A 1, A 2$, and $A 3$ in the model. Performance ratings range from 1, the highest, to 5, the lowest. Ratings of 3 through 5 are a small fraction of all ratings, so $2-5$ are merged into a single measure denoted by ' 0 ', resulting in a binary classification of a high or low performance, as in the model.

For estimation I focus on 1,426 managers who entered managerial positions between 1970 and 1979 at Level 1 with at least 16 years of education at entry and who, during the first ten years of tenure in the firm, experienced no change in the recorded number of years of education and have no level information missing. Due to the high separation rate in each year and tenure (see Table 1), I restrict attention to the first eight years of observations on these managers. In the estimation sample, no individual is older than 45 years at entry. (I also estimated the model on a larger sample that includes entrants into the firm at the original Levels 2, 3, and 4. This larger sample displays very similar features to those of the sample of entrants at Level 1 . See the Supplementary Appendix.)

Table 1 displays two patterns about level assignments at the firm and separation from the firm in the estimation sample. First, the percentage of managers at Level 1 rapidly decreases with tenure whereas the percentage of managers assigned to Levels 2 and 3 first increases then decreases with tenure. Second, separation rates are high in all tenures. By the seventh year, over half of those hired at Level 1 have separated. Table 2 converts these distributions into level-specific hazard rates of separation, retention at the same level, and promotion to the next level by tenure. Two further features emerge. First, the separation hazards are approximately constant in tenure. Second, the promotion hazards initially increase then decrease. All promotions are by one level and no demotion is ever observed.

These features of the sample are consistent with a gradual learning process by which managers are progressively assigned to higher levels or separate. That no manager is ever demoted even after

\footnotetext{
${ }^{14}$ Baker, Gibbs, and Holmström (1994b) report that the proportion of minorities and women at the firm has increased steadily. My copy of the data does not include information on gender or race.
} 
repeated low performance provides support for the presence of human capital accumulation. The intuition is that acquired human capital offsets the adverse impact of low performance on beliefs that a manager is of high ability. So, managers are retained at a level even after repeated low performance. Further, allowing human capital to be transferable across levels can also produce flexible tenure profiles for the hazard rate of promotion. Depending on how valuable human capital acquired at a level or overall with tenure is at higher levels, promotion rates may increase or decrease or be non-monotone with tenure in a level or with tenure in the firm. For instance, suppose that tenure in a given level or in the firm makes a manager more productive at a level but not at any other level. This task-specific property of acquired human capital would imply that the probability of promotion out of that level decreases with tenure, regardless of the number of past high ratings, as the greater task-specific human capital a manager acquires makes the manager better suited to that level. As argued in Section 5, the tenure profile of the promotion hazard is crucial for identifying the transferability of acquired human capital across levels.

Table 3 shows two patterns about performance ratings. (I omit statistics on ratings at Level 3 since I do not estimate the parameters of error in performance ratings at this level. See the Appendix for details.) First, the percentage of high ratings at Levels 1 and 2 decreases with tenure. Second, in any given tenure, high ratings are more likely at Level 2 than at Level 1 . As shown in the Supplementary Appendix in Table A.15, the percentage of high ratings are also higher among promoted managers than among unpromoted managers and, for promoted managers, among managers promoted early in their tenure in a level relative to those promoted later. These features reinforce the notion that managers are promoted based on their recorded performance. Since in the model human capital is acquired regardless of performance, the greater the sensitivity of the promotion hazard to past high performance, the greater the importance of learning. See Section 5.

Table 4 displays the distribution of wages (in 1988 U.S. dollars) by level and tenure, and Table 5 reports statistics on the distribution of wage changes by tenure. Four features emerge from Tables 4 and 5. Wages are higher at higher levels (note that the percentage of managers earning wages above $\$ 40 \mathrm{~K}$ increases with the level) and the level distribution of wages is more spread out at higher levels. Managers with higher performance ratings also receive higher wages on average; see BGH. Negative wage changes are frequent: over 20 percent at each tenure. Although average wages increase with tenure, their growth rate is not monotone.

To summarize, average wages increase with tenure and high performance, promotions sometimes occur after low performance, no demotions occur but wage decreases are common, especially after low performance. To account for these features, the model relies on the combination of the human capital and learning components as neither alone can reproduce these patterns. The human capital acquisition component of the model can naturally lead to increases in average wages with tenure that are unrelated to performance. Moreover, it can explain why promotions sometimes occur after low performance and why repeated poor performance does not lead to demotion. The human 
capital component, however, cannot generate wage decreases upon low performance. The learning component of the model, instead, naturally gives rise to wage increases upon high performance and wage decreases upon low performance. The learning component, however, also leads to demotions upon low performance, which are not observed in the data.

\section{Empirical Specification}

Here, I describe how I introduce unobserved heterogeneity into the model and the empirical specification of the output, human capital, and wage processes. In estimation I allow for classification error in performance ratings adapted from Keane and Sauer (2009) and measurement error in wages. Omitted details on the model's specification are contained in the Appendix and Supplementary Appendix. I also estimated the model on a larger sample that contains observations on managers entering into the firm at levels higher than Level 1. The estimates of the key parameters across the two samples are very similar if not indistinguishable and the model fit improved. See the Supplementary Appendix for details. Since I observe managers continuously employed at one firm only, from now on the subscript $t$ will denote tenure in the firm.

\subsection{Unobserved Heterogeneity}

I assume that the initial prior about ability varies unobservably across managers as do some parameters of the wage distribution. This variation is meant to capture persistent productivity differences among managers, observed by all model agents but not by the econometrician, that may be reflected in paid wages due to competition. ${ }^{15}$

Formally, in the spirit Heckman and Singer (1984), each manager is of unobserved skill type $i=1, \ldots, I$. In light of changes in likelihood values and the Akaike information criterion, I set $I=4$. The initial prior belief that any manager is of high ability takes on values $p_{i 1}$ with probability $q_{i}, i=1, \ldots, I$. Hence, since the probability of entry into the sample is a function of initial prior beliefs, whose distribution I estimate, sample selection is explicitly controlled for. The assumption implicit in this correction, consistent with equilibrium, is that unmeasured determinants of the initial probability of assignment, and thus of entry into the sample, are pure noise conditional on the distribution of the initial prior. These random factors reflect idiosyncratic variation in match quality from period to period, which are captured by the job-specific productivity shocks. Hence, for a manager of skill type $i, s_{i 1}=\left(p_{i 1}, h_{1}, i\right)$ is the initial state and

$$
s_{i t}=\left(p_{i t}, h_{t}, i\right)=\left(p_{i t}, h_{1}, t-1, k_{t-1}, i\right)
$$

\footnotetext{
${ }^{15}$ Recall that the data do not contain information on managers once they leave the firm. I control for this right censoring by allowing for both endogenous separations (that is, separations dependent on the prior) and exogenous separations (that is, separations independent of ability or performance).
} 
is the beginning-of-period state in $t \geq 2$. In particular, human capital is $h_{1}$ in $t=1$, captured by a manager's age, education, and year of entry into the firm, and $h_{t}=h\left(h_{1}, t-1, k_{t-1}\right)$ in $t>1$.

\subsection{Output and Human Capital}

Recall that human capital accrues deterministically with experience, as in a standard learning-bydoing setup, and affects a manager's high and low performance, $y_{f H k}(\cdot)$ and $y_{f L k}(\cdot)$, at the job $k$ of each firm $f$. I assume $y_{f L k}\left(h_{t}, i\right)=\gamma_{f k}+\gamma_{L i} h_{t}$ and $y_{f H k}\left(h_{t}, i\right)=y_{f L k}\left(h_{t}\right)+\gamma_{f H i}(t-1)$. By the same logic as in (1), a manager's expected output at job $k$ of firm $f$ in $t$ is

$$
y_{f}\left(s_{i t}, k\right)+\varepsilon_{f k t}=\underbrace{\gamma_{f k}+\gamma_{L i} h_{t}+\beta_{f k} \gamma_{f H i}(t-1)}_{b_{f k}\left(h_{t}, i\right)}+\underbrace{\left(\alpha_{f k}-\beta_{f k}\right) \gamma_{f H i}(t-1)}_{c_{f k}\left(h_{t}, i\right)} p_{i t}+\varepsilon_{f k t} .
$$

In this expression, as before, the human capital process is subsumed by $b_{f k t}=b_{f k}\left(h_{t}, i\right)$ and $c_{f k t}=c_{f k}\left(h_{t}, i\right)$. Note that $b_{f k t}$ and $c_{f k t}$ change deterministically with a manager's experience, but the rate at which they change differs by firm, $f$, and job, $k$. Due to data limitations, I parameterize the output and human capital process slightly differently at my firm and at its competitors.

Firm A. Since I do not observe output at my firm, I can only identify output differences through managers' transitions across levels. See the details in the Appendix. Hence, I assume that $\gamma_{A k}=0$ and also assume that all dependence on $i$ is through $p_{i t}$. Given that the empirical probabilities of assignment to any level do not vary much with a manager's entry characteristics, $h_{1}$, conditional on tenure, performance, and previous period assignment, in practice the relevant state for $h_{t}$ reduces to $\left(t-1, k_{t-1}\right) \cdot{ }^{16}$ Based on these observations, (10) becomes

$$
y_{A}\left(s_{i t}, k\right)+\varepsilon_{A k t}=\underbrace{\gamma_{L} h_{t}+\beta_{A k} \gamma_{A H}(t-1)}_{b_{A k}\left(k_{t-1}, t-1\right)}+\underbrace{\left(\alpha_{A k}-\beta_{A k}\right) \gamma_{A H}(t-1)}_{c_{A k}(t-1)} p_{i t}+\varepsilon_{A k t} .
$$

In (11) $b_{A k}\left(k_{t-1}, t-1\right)$ depends on a manager's current assignment, $k$, tenure, $t-1$, and previous period assignment, $k_{t-1}$, whereas $c_{A k}(t-1)$ depends on only a manager's current assignment, $k$, and tenure, $t-1$. I estimated $b_{A k}\left(k_{t-1}, t-1\right)$ and $c_{A k}(t-1)$ normalizing the variance of $\varepsilon_{A k t}$ to $\pi^{2} / 6$. (For simplicity, from now on I will drop the subscript $A$ and let the subscript $t$ denote dependence on tenure so that $b_{A k}\left(k_{t-1}, t-1\right)$ becomes $b_{k t}\left(k_{t-1}\right)$ and $c_{A k}(t-1)$ becomes $\left.c_{k t}.\right)$

This simple specification of the output and human capital process allows for different degrees of transferability of the human capital acquired at a level to other levels of firm $A$. I define the human capital acquired at Level $k$ to be task-general, or transferable across the levels of firm $A$, if $b_{k^{\prime} t}(k) \geq b_{k^{\prime} t}\left(k^{\prime}\right)$ for $k^{\prime} \neq k$, and task-specific otherwise. For example, if the human capital acquired at Level 1 or 2 is more productive at Level 3 than the human capital acquired at Level 3, then

\footnotetext{
${ }^{16}$ When estimating the model on the larger sample that also contains observations on entrants at levels higher than Level 1, I allow for $h_{1}$ to vary across managers entering at different levels.
} 
the human capital acquired at Level 1 or 2 is task-general. On the contrary, an extreme case of task-specific human capital is when the human capital acquired at Level 3 only affects output at Level 3.

This specification is also consistent with different degrees of transferability across levels of the human capital acquired with tenure in the firm. I define the human capital acquired with tenure in the firm to be task-general if the tenure profiles of the parameters $b_{k t}\left(k_{t-1}\right)$ and $c_{k t}$ at different levels are positively correlated. (See Gibbons and Waldman (2006) for a similar definition.) For example, if the tenure profiles of these parameters at Levels 1 and 2 are highly correlated, then human capital acquired with tenure is task-general across Levels 1 and 2.

Other Firms. Since my data contain information about one firm only, for firm $A$ 's competitors I first assume that $\gamma_{f H i}(t-1)$ is independent of $t-1$ for simplicity. Second, I maintain that $\beta_{f k} \gamma_{f H i}$ and $\left(\alpha_{f k}-\beta_{f k}\right) \gamma_{f H i}$ are constant across firms, $f$, and jobs, $k$. Hence, I denote $\gamma_{L i} h_{t}+\beta_{f k} \gamma_{f H i}$ by $b\left(h_{t}, i\right)$ and $\left(\alpha_{f k}-\beta_{f k}\right) \gamma_{f H i}$ by $c(i)$ suppressing the dependence of these terms on $f$ and $k$. Thus, (10) for a firm $f$ becomes

$$
y_{f}\left(s_{i t}, k\right)+\varepsilon_{f k t}=\gamma_{f k}+\underbrace{\gamma_{L i} h_{t}+\beta_{f k} \gamma_{f H i}}_{b\left(h_{t}, i\right)}+\underbrace{\left(\alpha_{f k}-\beta_{f k}\right) \gamma_{f H i}}_{c(i)} p_{i t}+\varepsilon_{f k t} .
$$

\subsection{Wages}

As shown in (9), Bertrand competition implies that a manager's wage reflects the technology of the best competitor of firm $A$ for that manager. Hence, the extent to which paid wages are affected by the prior about a manager's ability and by a manager's acquired human capital at firm $A$ provides information about the extent to which unobservable ability and observable human capital, respectively, are transferable across my firm and its competitors. By (9), (12), the properties of extreme value distributions, and equilibrium, the wage of a manager of skill type $i$ at firm $A$ in $t$ is

$$
w_{A i t}=\underbrace{b\left(h_{t}, i\right)+c(i) p_{i t}}_{\varpi_{i}\left(h_{1}\right)+\omega_{1} \cdot(t-1)+c(i) p_{i t}}+\underbrace{\ln \sum_{g \neq A, k \in K^{g}} \exp \left\{\gamma_{g k}+\Psi_{k}\left(s_{i t}, k_{A t}\right)\right\}}_{\psi_{i}\left(h_{1}, k_{A t}\right)+\psi_{k_{A t}} \cdot(t-1)+\psi_{1 i}\left(k_{A t}\right) \cdot p_{i t}}+\varepsilon_{0 t} .
$$

See Corollary 1 in the Supplementary Appendix for a proof. As (9) and (13) make clear, if firm $A$ has monopsony power in the labor market, then a manager's current assignment at firm $A$ affects paid wages only to the extent that it affects the compensating wage differentials $\Psi_{k}\left(s_{t}, k_{A t}\right)$ between job $k$ of the competitor of firm $A$ with technology $g$ and job $k_{A t}$ of firm $A$.

I specify flexibly the dependence of $b\left(h_{t}, i\right)$ on $h_{t}=h\left(h_{1}, t-1, k_{t-1}\right)$ and $i$ as well as the dependence of $\Psi_{k}$ on $s_{i t}=\left(p_{i t}, h_{t}, i\right)$, as shown beneath the first three terms of (13). In particular, I specify $b\left(h_{t}, i\right)$ as $\varpi_{i}\left(h_{1}\right)+\omega_{1} \cdot(t-1)$ based on the following three considerations. First, I assume that initial human capital, $h_{1}$, and tenure, $t-1$, affect $b(\cdot)$ in a linearly separable way for simplicity 
and consistency with the data. Second, in the data wages at any level do not display any significant dependence on $k_{A t-1}$, conditional on manager characteristics and current and past performance, so I ignore it. Third, the dependence on $i$ is captured by $\varpi_{i}\left(h_{1}\right)$ only: $\omega_{1}$ is assumed to be independent of $i$. The reason why $\omega_{1}$ is specified as independent of $i$ is as follows. I allow for a tenure term only at Level 1 to capture the different behavior of wages at Level 1 in high tenures compared to Levels 2 and 3 - from Table 4, the fraction of managers at Level 1 receiving wages between $\$ 20 \mathrm{~K}$ and $\$ 40 \mathrm{~K}$ steadily increases from the fifth year of tenure on. ${ }^{17}$ Given the small number of observations at Level 1 in those tenures, I assumed $\omega_{1}$ is independent of $i$.

Consider next the third term of (13), which contains the compensating wage differential terms $\Psi_{k}$. I specify it semiparametrically as a polynomial in $p_{i t}$ whose coefficients capture the dependence of this term on the other elements of $s_{i t}$ and on $k_{A t}$. Following the same logic motivating the parameterization of $b(\cdot)$, I specify the coefficient on the term of degree zero of this polynomial as $\psi_{i}\left(h_{1}, k_{A t}\right)+\psi_{k_{A t}} \cdot(t-1)$ and the coefficients on the terms of degree $r \geq 1$ as $\psi_{r i}\left(k_{A t}\right)$. (In estimation, coefficients on terms of degree higher than one have proved unimportant at all trial parameter values and difficult to estimate with any precision, so I ignored them.) From (13), by rearranging terms I then obtain

$$
w_{A i t}=\varpi_{i}\left(h_{1}\right)+\psi_{i}\left(h_{1}, k_{A t}\right)+\left(\omega_{1}+\psi_{k_{A t}}\right) \cdot(t-1)+\left[c(i)+\psi_{1 i}\left(k_{A t}\right)\right] p_{i t}+\varepsilon_{0 t},
$$

which leads to a sharing rule of the match surplus between firm $A$ and a manager that varies for the same manager over time and across managers as a function of the prior, $p_{i t}$, acquired human capital, $h_{1}$ and $t-1$, and the current assignment at firm $A, k_{A t}$. The case in which the labor market is (nearly) perfectly competitive obtains when two conditions hold: the intercept term of (14) is close to $b_{k t}(\cdot)$, the intercept term of expected output at job $k_{A t}$ in (11), and the slope term of (14) is close to $c_{k t}$, the slope term of expected output at job $k_{A t}$ in (11). I can then provide a measure of the monopsony power of firm $A$ by comparing average paid wages to average estimated output (averaged over productivity shocks).

To obtain the estimated wage equation, define now $\omega_{i}\left(h_{1}, k_{A t}\right)=\varpi_{i}\left(h_{1}\right)+\psi_{i}\left(h_{1}, k_{A t}\right), \omega_{1 t}=$ $\omega_{1}+\psi_{k_{A t}}$ for $k_{A t}=1$ and $\omega_{1 t}=0$ otherwise (recall that a tenure term is estimated only at Level 1), and $\omega_{2 i}\left(k_{A t}\right)=c(i)+\psi_{1 i}\left(k_{A t}\right)$. Since descriptively the dependence of wages on a manager's current and past performance is similar across levels, to conserve on parameters I maintain $\omega_{2 i}\left(k_{A t}\right)=\omega_{2 i}$. To account for unmeasured aspects of firm and manager behavior, as well as recording error, I allow wages to be contaminated by an additive generalized extreme value disturbance, $\varepsilon_{k i t}^{m}$, where $k=k_{A t}$. Since $u_{k i t} \equiv \varepsilon_{0 t}+\varepsilon_{k i t}^{m}$ is logistically distributed, I approximate the distribution of $u_{k i t}$ by a normal distribution with mean zero and variance $\sigma_{i k}^{2}$, to allow for the possibility that managers

\footnotetext{
${ }^{17}$ Empirically, tenure terms at Levels 2 and 3 are unimportant for wages, conditional on managers' characteristics and current and lagged performance (proxies for the prior). Even in reduced form, these tenure effects, conditional on managers' observed characteristics and current and lagged outcomes, cannot be estimated with much precision.
} 
of different skill types $i$ or at different levels $k$ at firm $A$ have access to different labor market opportunities, reflected in their wages. Note also that the observed wage distribution at each level is close to a lognormal distribution and managers are salaried rather than hourly employees. Based on these observations, I interpret the model as determining a process for $\ln \left(w_{\text {Ait }}^{o}\right)$, where $w_{\text {Ait }}^{o}$ is the observed wage. With $k=k_{A t}$, the specification I estimate is

$$
\begin{gathered}
\ln \left(w_{\text {Ait }}^{o}\right)=\omega_{i}\left(h_{1}, k\right)+\omega_{1 t} \cdot(t-1) I(k=1)+\omega_{2 i} p_{i t}+u_{k i t}, \\
\omega_{i}\left(h_{1}, k\right)=\varpi_{0 i k}+\varpi_{1 k} a g e+\varpi_{2 k} a g e^{2}+\varpi_{3 k} e d u+\sum_{m=1}^{9} \varpi_{y m} I(\text { year }=m) .
\end{gathered}
$$

Here, age and edu denote a manager's age and number of years of completed education, respectively, at entry into the firm. The coefficients $\varpi_{1 k}, \varpi_{2 k}, \varpi_{3 k}$, and $\varpi_{y m}$ capture the degree of transferability across firms of the human capital acquired by managers before entry into my firm. Specifically, the term $I($ year $=m)$ is an indicator function that equals one if, and only if, a manager's year of entry into the firm is $m$, where $m$ corresponds to the calendar year $197 m$. The coefficients $\varpi_{y m}$ allow for the possibility that business cycle conditions at the time of hiring are permanently reflected in the wages paid by the firm. BGH find such effects important, even after several years of tenure; see also Waldman (2012). The coefficient $\omega_{2 i}$ captures the degree of transferability of unobserved ability across firm $A$ and its competitors.

\section{Identification}

Here I provide an intuitive overview of the identification of the model. I relegate a more formal discussion to the Supplementary Appendix. Specifically, there I show how repeated information on performance ratings allows me to identify the learning parameters $\left\{\alpha_{k}, \beta_{k}\right\}_{k=1}^{3}$, even in the presence of classification error in performance ratings, and provide conditions for the nonparametric identification of the process governing the evolution of the state variables, that is, the prior and acquired human capital, and of the discrete choice variable, that is, level assignment, based on Kasahara and Shimotsu (2009) and Hu and Shum (2012). ${ }^{18}$

Learning. To understand the additional identifying power that information on performance ratings provides, consider first the standard argument for the identification of the initial prior and the learning parameters if only repeated information on level assignment were available. (See Crawford and Shum (2005) for a standard reference in the context of demand estimation.) At each level and tenure, the hazard rates of retention at a level, promotion to a higher level, and demotion to a lower level provide information about the initial prior and $\left\{\alpha_{k}, \beta_{k}\right\}_{k=1}^{3}$. In particular, the extent to which job switching varies with the number of periods managers have been assigned to a given level helps identify $\left\{\alpha_{k}, \beta_{k}\right\}_{k=1}^{3}$ whereas differences in the assignment probabilities in early versus

\footnotetext{
${ }^{18}$ I thank Aureo de Paula, Hiro Kasahara, Kyoo il Kim, and Matt Shum for very helpful discussions.
} 
late tenures help identify $\left\{p_{i 1}, q_{i}\right\}_{i}^{4}$.

Now, differently from common estimation exercises of learning models, my data also include an additional key piece of information that provides a crucial source of identification for $\left\{\alpha_{k}, \beta_{k}\right\}_{k=1}^{3}$ : the performance ratings of all managers in each year of employment, which are the empirical counterparts of a manager's performance in the model. Formally, the observed distribution of performance at each level is a mixture of the distribution of performance of managers of high and low (unobserved) ability. As shown in Section 1.1, in the absence of classification error, the fractions of managers with a high rating at the end of the first and second year of tenure at Level 1 are sufficient to identify $\alpha_{1}$ and $\beta_{1}$. By the same argument, the fractions of promoted individuals from Level 1 to 2 with one and two consecutive high ratings at Level 2 identify $\alpha_{2}$ and $\beta_{2}$. A similar argument applies to Level 3. The same logic holds in the presence of classification error in performance ratings.

Learning vs. Human Capital Acquisition. Recall that human capital evolves deterministically with experience, as in a standard learning-by-doing setup, but has no impact on belief updating. Based on this framework, the crucial feature of the data that allows me to distinguish the two processes, when both are present, is the tenure profile of the hazard rate of promotion and its dependence on a manager's performance. To see how, consider an extreme case in which learning is not present in the data but human capital acquisition is. Recall from (11) that human capital is acquired by a manager independently of performance. Thus, when learning is not present, given a manager's history of level assignments, the probability of promotion to a higher level is invariant to the number of realized high ratings. Instead, as learning becomes more important, the hazard rate of promotion becomes more dependent on the number of past high ratings. Hence, for any given history of level assignments, the sensitivity of the promotion rate to the number of realized high ratings distinguishes learning from human capital acquisition when both processes are present. See the Appendix for a discussion of how the degree of transferability of acquired human capital across levels of my firm and of unobserved and acquired human capital across firms can be detected, respectively, based on the tenure profile of the hazard of promotion and the correlation between performance and wages.

Wages. Recall from (15) that, conditional on beliefs, (log) wages are determined by a linear semiparametric regression model with a random intercept, $\omega_{i}\left(h_{1}, k\right)+\omega_{1 t} \cdot(t-1) I(k=1)$, which is individual- and level-specific and varies with tenure, and with a random slope, $\omega_{2 i}$, on the typespecific prior $p_{i t}$. A large literature examines the nonparametric identification of the distribution of random coefficients in the linear regression model; see Hoderlein, Klemelä, and Mammen (2010) for a recent reference. By a standard moment argument, it is easy to show that the intercept function and the coefficient on the prior can be recovered. Information on wages also helps pin down the distribution of initial priors. In particular, the skewness of the distribution of (log) wages at Level 1 in the first year of tenure, the number and locations of its modes, and the dispersion of wage 
observations around them, provide a further source of identification for $\left\{p_{i 1}, q_{i 1}\right\}$.

\section{Estimation Results}

Tables 6A through 6I report the values of the parameters, estimated by full-information, fullsolution, non-parametric maximum likelihood on the sample of managers who entered into the firm at Level 1. In estimation the discount factor, $\delta$, is fixed at 0.95. All parameters are significant at the one percent level. I relegate a discussion of the model fit and of goodness-of-fit test results to the Appendix. Overall, as Tables 1-4 show, the estimated model successfully captures the patterns of managers' transitions across the levels of the firm's hierarchy, which are nonlinear and nonmonotone in tenure, and of separation from the firm as well as the distribution of wages and performance at the main levels at each tenure. (The Supplementary Appendix derives the likelihood function, explains the numerical solution of the model, reports estimates on the sample that includes managers who entered into the firm at levels higher than Level 1, and presents a Monte Carlo exercise that demonstrates parameter identification. There I also explain the inferences that, based on the estimates of the wage parameters, can be drawn about the technology of the competitors of my firm. I find the informativeness of their jobs similar to that of the jobs of my firm, albeit slightly higher.)

Uncertainty and Learning. Three findings emerge from the estimates of the learning parameters in Table 6 A. First, the distribution of initial priors, $\left\{p_{i 1}, q_{i}\right\}_{i=1}^{4}$, implies a large degree of uncertainty about a manager's ability and dispersion in information at hiring. Indeed, the average initial prior probability that a newly hired manager is of high ability is 0.473 but initial priors range from 0.338 for skill type 1 to 0.607 for skill type 4 with a standard deviation of 0.102 .

Second, the learning parameters $\left\{\alpha_{k}, \beta_{k}\right\}_{k=1}^{3}$ in Table 6B imply that Level 1 is the most informative, and hence plays an important screening role by allowing the firm to gather information about managers' ability. By the Blackwell criterion, the ordering of jobs by their informativeness, from lowest to highest, is Level 2, Level 3, and Level $1 .{ }^{19}$ Interestingly, the opposite ordering occurs by the probability of success of a manager of high or low ability, which leads to a trade-off between productivity and learning through job assignment as in a typical multi-armed bandit.

Third, learning is overall gradual but the speed of learning varies across levels and types of managers. To measure the implied speed of learning at each job, I compute how many years of consecutive high performance it takes to infer with a 90 percent chance that a manager is of high ability. At Level 1 at the average prior it takes 20 years. Starting with the same prior at Level 2 or 3 , this process takes 23 years. For managers of the fourth skill type, however, this level of certainty

\footnotetext{
${ }^{19}$ By the Blackwell criterion of informativeness (Blackwell (1951)), job $k$ is more informative than job $k^{\prime}$ if the posterior beliefs reached after performance is observed at job $k$ at the end of a period second-order stochastically dominate the posterior beliefs reached after performance is observed at job $k^{\prime}$.
} 
takes only 15, 18, and 17 years at Levels 1,2 , and 3, respectively. ${ }^{20}$ This finding is consistent with the fact that uncertainty at entry into the firm is estimated to be large even for managers who arguably have several years of labor market experience.

Output and Human Capital. From the estimates of the output and human capital parameters in Table 6D, it first emerges that human capital acquired at Levels 2 and 3 is highly task-specific. To see this, note that the difference $b_{1 t}(L 2)-b_{1 t}(L 1)$ is large and negative in $4 \leq t \leq 7$ : managers assigned to Level 2 in $t-1$ and to Level 1 in $t$ produce $b_{1 t}(L 2)-b_{1 t}(L 1)$ less in $t$ at any prior than managers assigned to Level 1 in $t-1$ and $t$. Thus, demoting a manager from Level 2 to 1 is costly for the firm in medium and high tenures. Similarly, the difference $b_{3 t}(L 3)-b_{3 t}(L 2)$ is large and positive in $4 \leq t \leq 7$ : managers assigned to Level 3 in $t-1$ and $t$ at any prior produce $b_{3 t}(L 3)-b_{3 t}(L 2)$ more in $t$ than managers assigned to Level 2 in $t-1$ and to Level 3 in $t$. Thus, tenure in Level 3 is valuable for output at Level 3. Second, it appears that human capital acquired with tenure in the firm is highly transferable across levels, at least for the part that affects $c_{k t}$. To see this, note that the parameters $c_{k t}$ at each Level $k$ display the same (approximately hump-shaped) profile with tenure. For example, $c_{2 t}$ starts at zero, peaks at $t=2$, and essentially declines thereafter. In practice, the tenure profiles of the parameters $c_{k t}$ help the model account for the observed hump-shaped pattern of the hazard rates of promotion out of Levels 1 and 2.

Within-Firm Job Assignment Policy. At the estimated values of the parameters of learning, output, and human capital, the firm's optimal assignment policy implies that retained managers have higher priors than newly hired managers and belief variance is higher at lower levels. Manager selection occurs not only through retention but also through promotion: on average managers at higher levels have higher unobserved ability and acquired human capital.

Wages. The estimates of the wage process in Tables $6 \mathrm{~F}-6 \mathrm{I}$ are similar to those in the literature concerning the return to entry age, the size of wage increases at promotion, the convexity of wages in job levels, and the magnitude of wage growth on the job. They provide no evidence that this single firm is anomalous within the broader labor market. For instance, Table 6F implies that promotions lead to sizeable permanent increases in wages: a promotion from Level 1 to 2 implies an increase in annual wages of $\$ 781$, whereas a promotion from Level 2 to 3 implies an increase in annual wages of $\$ 5,723 .^{21}$ So, wages are quite convex in the job level. These results are, qualitatively and quantitatively, in line with much of the literature on internal labor markets. See Gibbons and Waldman (1999a,b), Belzil and Bognanno (2008), and Waldman (2012).

As for managers' observed characteristics, note that the coefficients on entry age and education in Table 6G imply that human capital acquired before entry is transferable across other firms and my

\footnotetext{
${ }^{20}$ These results are consistent with the findings of Nagypál (2007) on the importance of learning for labor market turnover. From Figure 7 in her paper (where all plots are truncated at the tenth year of tenure), the convergence of beliefs, as reflected in the tenure profile of match quality and output, seems to occur past the tenth tenure year.

${ }^{21}$ These wage increases are calculated by first averaging across manager skill types the level-specific intercepts of mean log wages and then computing the differences in these values after converting them back from logs to levels.
} 
firm. For example, at Levels 1 and 2, the effect of an additional year of age, evaluated at the average age at entry of 29.71 years, is 1.0 percent (from $\left.\varpi_{1}+2 \varpi_{2}(29.71)=0.0102\right)$, whereas the effect of an additional year of schooling is 2.2 percent (from $\varpi_{3}=0.022$ ). At Level 3 the corresponding numbers are 0.4 percent (from $\varpi_{13}+2 \varpi_{23}(29.71)=0.0041$ ) and 2.1 percent (from $\varpi_{33}=0.021$ ). These estimates of the effects of age and education on wages are comparable to analogous findings in the literature. For instance, Belzil and Bognanno (2008, Table 1) estimate coefficients of 0.0127 and 0.0494 for the (just linear) impact of age and education on (log) wages in a large multi-firm sample of U.S. executives observed between 1981 and 1988, a window of observation very similar to mine. Not surprisingly, since I restrict attention to a highly educated group of individuals, the effect of education on wages that I estimate is smaller than that of Belzil and Bognanno (2008).

The estimated tenure effect $\omega_{12}$ at Level 1 in Table $6 \mathrm{G}$ is small (and zero at the other levels), which suggests that human capital acquired at the firm is not very transferable to other firms. ${ }^{22}$ Since in the wage equation age and education are fixed at their entry values, this finding implies that wage dynamics is driven almost exclusively by learning and competition. ${ }^{23}$ I will comment further on this point below.

As for managers' unobserved characteristics, note that the coefficients $\left\{\omega_{2 i}\right\}_{i=1}^{4}$ on the prior in Table $6 \mathrm{I}$ are sizeable, positive, and significant, implying, as anticipated, that average wages increase with the prior. Thus, unobservable ability is transferable across firms, which suggests that matching based on this ability is positive assortative in the market for managers. The standard deviation of the wage disturbance, $\left\{\sigma_{i k}\right\}_{i=1}^{4}$, essentially decreases with the level. Despite this pattern, the model implies that the variance of wages is higher at higher levels as in the data: the estimated standard deviation of wages at Levels 1,2 , and 3 , pooled across tenures, is $\$ 6,936$ at Level 1, $\$ 7,077$ at Level 2, and $\$ 8,046$ at Level 3. (See the note to Table 4 for the data and Table 7A for the model.) Hence, the model's prediction that wage dispersion grows across levels is generated by the endogenous mechanisms of the model, such as the increased dispersion in information, rather than by idiosyncratic unexplained factors.

Monopsony Power. Overall the estimates confirm the importance of explicitly modeling imperfect competition in the labor market. To see why, first note that if my firm behaved as a perfect competitor, then the correlation between average estimated output (averaged over productivity shocks at each job) and average wages would be close to one. Instead, this correlation over the first seven years of tenure is 0.478 at Level 1, 0.380 at Level 2, and 0.521 at Level 3 (excluding the third tenure year, in the case of Level 3; otherwise, the correlation is much lower). This finding implies that wage premia at promotion reflect differences in the prospect for learning, human capital acquisition, and exogenous separation between other firms in the market and my firm rather than just higher output at higher levels at my firm. To see this, note from Table $6 \mathrm{~F}$ that the wage

\footnotetext{
${ }^{22}$ Note that $\omega_{1 t}=\omega_{12} I(t<5)+\omega_{15} I(t \geq 5)$ where $\omega_{15}=-\omega_{12}$. See the Appendix.

${ }^{23}$ The estimated year-of-entry effects in Table $6 \mathrm{H}$ are consistent with the recession between 1974 and 1979 , which depressed the wages of entrants in those years relative to the wages of those who entered in earlier years.
} 
intercepts of each manager skill type are higher at higher levels and higher than the corresponding (expected) output intercepts, that is, the coefficients $b_{k t}(\cdot)$ in Table 6D. Thus, wage premia at promotion capture the fact that managers at higher levels sacrifice relatively more valuable prospects for learning and human capital acquisition at other firms than they do at lower levels.

Wage Growth. Overall the estimates imply an increase in average wages of 19.4 percent over the first seven years of tenure in the firm, corresponding to an average yearly growth rate of 3.2 percent. (Wage growth over the first seven years of tenure is higher when separating managers are excluded, 19.4 percent versus 18.5 percent, which suggests the presence of selection through retention.) This magnitude of wage growth on the job is consistent with the estimates of within-job wage growth by Topel (1991) (see his Table 2) and is bracketed by those of Buchinsky, Fougère, Kramarz, and Tchernis (2010) (see their Figure 2). Specifically, based on their estimates from the Panel Study of Income Dynamics, Buchinsky et al. (2010) document that yearly wage growth is between 2.9 percent and 8.7 percent for individuals with a college degree. Thus, my estimate of 3.2 percent lies between their two estimates. ${ }^{24}$

Lastly, observe that $(\log )$ wage growth can be decomposed into the contribution of the three terms on the right side of (15) - the contribution of the fourth term, $u_{i k t}$, is effectively zero. An interpretation of this decomposition is that the first term, $\omega_{i}\left(h_{1}, k\right)$, captures the effect of unobserved skills, initial human capital, and job assignment, the second term, $\omega_{1 t} \cdot(t-1) I(k=1)$, captures the effect of human capital acquired with tenure, and the third term, $\omega_{2 i} p_{i t}$, captures the effect of learning. Over the first seven years of tenure in the firm, the first term accounts for more than 98 percent of the increase in log wages whereas the second term accounts approximately for -1.6 percent (unbalanced panel) to 0 percent (balanced panel). Based on this decomposition, one might conclude that learning accounts only for a trivial percentage of wage growth on the job.

This interpretation, however, is problematic since job assignment is determined by the processes of learning and human capital acquisition at the firm: the 98 percent contribution of initial human capital and job assignment to wage growth includes the dynamics of learning and acquired human capital. These two processes, then, contribute to wage growth over and above what is accounted for by the second and third terms of (15) through their impact on the dynamics of job assignment. In particular, learning has an indirect effect on wage growth through its effect on promotions: learning leads higher-ability managers to be more quickly promoted to higher levels, at which they earn higher wages. I uncover this indirect effect of learning through the counterfactual experiments discussed next.

\footnotetext{
${ }^{24}$ Buchinsky et al. (2010) document that, over the 18-year period they analyze, wage growth for individuals with a college degree is $0.94 \mathrm{log}$ points in the case of individuals with 5 years of experience and 2 years of tenure, and 0.42 $\log$ points in the case of individuals with 15 years of experience and 6 years of tenure. The implied yearly growth rate is between 2.9 percent (from $[\exp (0.42)-1] 100 / 18)$ and 8.7 percent (from $[\exp (0.94)-1] 100 / 18)$.
} 


\section{Learning, Human Capital, and Persistent Uncertainty}

Here I assess the roles of learning, human capital acquisition, and persistent uncertainty about ability for the observed patterns of jobs and wages at my firm.

The Role of Learning and Human Capital. To evaluate the impact of learning on the dynamics of jobs and wages in the baseline model, I compare the predictions of the baseline model to the case when learning is absent. The no learning version of the model assumes that all jobs are uninformative about ability $\left(\beta_{k}=\alpha_{k}\right.$ for all $k$ ). Table $7 \mathrm{~A}$ compares statistics for wages in the two models, with and without learning. Overall learning generates faster wage growth and greater wage dispersion with tenure. Over the course of the first seven years at the firm, learning accounts for 26 percent (from $(19.4-15.4) 100 / 15.4=26.0$ percent) of measured wage growth and 23 percent (from $(8,046-6,534) 100 / 6,534=23.1$ percent) of the variability of wages at Level 3 (with lower percentages at lower levels), the rest being accounted for by human capital acquisition before entry into the firm and with tenure at the firm. ${ }^{25}$ A key channel for beliefs to affect wages, as anticipated, is job assignment. Table $7 \mathrm{~B}$ displays the distribution of managers across levels by tenure in the baseline and no learning models. In the baseline model, by the third year of tenure, about 9 percent of managers have been promoted to Level 3, whereas in the no learning model, fewer than 1 percent have. By the seventh year, the fraction of managers at Level 3 is 32 percent in the baseline model and 24 percent in the no learning model. With learning, higher-ability managers are more quickly promoted to higher-level jobs at which they are paid higher wages. Note also that despite human capital acquired at the firm being essentially firm-specific, the impact of human capital acquisition on wage growth is substantial and it occurs through the dynamics of job assignment as well. Human capital acquired with tenure makes managers more productive at higher levels, at which they earn higher wages. Further, human capital acquired at a level essentially prevents demotions from occurring and, thus, reduces the wage loss that managers would otherwise experience upon low performance. Both channels imply a positive effect of human capital on wages.

Comparison with the Literature on Learning. Here I find the total effect of learning on wages to be sizeable despite the direct effect discussed above being small. Note that this finding is consistent with the estimates of the importance of learning in the literature. That the direct effect of learning on wages is quantitatively unimportant is in line with the results of Gibbons et al. (2005), Lluis (2005), and Hunnes (2012) (at least for the sample of technical white collar workers that Hunnes considers). In addition, by replicating the analysis of Lluis (2005) and Hunnes (2012) in my data, based on the same instrumental variable approach as in Gibbons et al. (2005), I find the impact of learning mostly insignificant; details are available upon request. On the other hand, that the

\footnotetext{
${ }^{25}$ If, when $\alpha_{k}$ and $\beta_{k}$ change, output levels are adjusted so as to keep expected output at each level equal to the baseline value at each prior, the experiment leads to smaller wage growth. Such an exercise, however, ignores the fact that changes in the informational structure affect expected output, by affecting the probability of high and low performance, as well as future output, by affecting the amount of information generated. This dual effect of changes in $\alpha_{k}$ and $\beta_{k}$ is central to the incentives the firm and the managers face when actively learning.
} 
indirect effect of learning may be sizeable is consistent, for instance, with the findings of Nagypál (2007) on the importance of learning for labor market turnover and Papageorgiou (2012) on the importance of learning for occupational mobility. For related work on the importance of learning in the industrial organization literature, see Erdem and Keane (1996), Crawford and Shum (2005), Ching (2010), and the review by Ching, Erdem, and Keane (2011).

The Role of Learning through Experimentation. Next, consider the counterfactual exercise when experimentation is precluded, that is, when all jobs are equally informative. I focus on one experiment, referred to as equal informativeness as Level 1. Jobs at Levels 2 and 3 are made as informative as at Level 1 by setting $\alpha_{k}$ and $\beta_{k}$ equal to their estimated values at Level 1 while leaving all other parameters unchanged. Results for the analogous experiments of equal informativeness as Levels 2 and 3 are in the Supplementary Appendix (Tables A.12-A.14). Table 7C shows that, without experimentation, nearly all of the managers who do not separate from the firm are quickly assigned to Level 3 and stay there. Indeed, apart from the first two years of tenure, the proportion of managers assigned to Level 1 is very small in each tenure. This finding occurs even though learning takes place slowly over time, as discussed. Thus, the speed of promotions is not itself informative about the speed of learning in a job. Rather, the pace of promotions reflects the relative informativeness or, equivalently, the relative speed of learning of different jobs and, thus, the scope for experimentation. This effect proves to be quantitatively important for mobility in the firm as well as wage growth. As Table 7A shows, rapid promotions are accompanied by rapid wage growth. By the second year of tenure, without experimentation wage growth is 17.6 percent, nearly twice as large as in the baseline model. By the fourth year of tenure, managers experience a higher wage growth than their cumulative wage growth over seven years in the baseline model - after that, wage growth is fairly flat. Over the first seven years of tenure, cumulative wage growth would be 20 percent higher (from $20.1=(23.3-19.4) 100 / 19.4)$ in the absence of experimentation. Hence, learning without experimentation would lead to higher wage growth than the wage growth generated by learning with experimentation, measured above.

The Role of Persistent Uncertainty. To assess the role of persistent uncertainty, I conduct two experiments. In the fast learning at Level 1 case, jobs at Level 1 are made to be nearly perfectly informative about ability, with $\alpha_{1}=0.99$ and $\beta_{1}=0.01$, whereas the other parameters are fixed at their baseline values. See the Appendix for the case of fast learning at Level 2. Table 7A shows the implications for wages and Table 7B for job assignments. Over the first seven years of tenure, faster learning at Level 1 leads wages to grow more than 60 percent compared to approximately 20 percent in the baseline model. Wage dispersion at each level also increases: the standard deviation of wages at Level 3 is over five times larger than in the baseline model. Promotions to Level 3 are also faster than in the baseline model: by the fourth year of tenure, 30 percent of managers are already assigned to Level $3 .^{26}$ Hence, overall persistent uncertainty about ability substantially

\footnotetext{
${ }^{26}$ If, when $\alpha_{k}$ and $\beta_{k}$ change, output levels are adjusted so as to keep expected output at each level equal to the
} 
compresses wage levels and wage growth with tenure.

\section{Conclusion}

This paper is the first to develop and estimate a model that integrates job assignment, learning, and human capital acquisition to account for rich patterns of individual careers in firms. Using detailed data on individual job assignments, wages, and performance ratings, I can separately identify the process for learning and human capital acquisition. These data allow me to recover explicit measures of the uncertainty about workers' abilities at the time of hiring, assess the informativeness of each of the firm's jobs, estimate the implied speed of learning at each job, and measure the relative contribution of learning and human capital acquisition to wage growth on the job.

My results show that the impact of learning on wage growth, through its indirect effect on the dynamics of job assignment, is much larger than the impact usually documented through reducedform estimation of the wage process alone. These reduced-form estimates capture only a part of the impact of learning on wages, namely its direct and contemporaneous effect, typically found to be small or insignificant. I argue that the key impact of learning on wages is through its indirect effect on the dynamics of job assignment: learning leads to faster promotions, which in turn lead to higher wages. The combination of the direct and indirect effects leads to a large total effect of learning on wages: learning accounts for more than one quarter of cumulative wage growth on the job over the first seven years of tenure, with the rest essentially from human capital acquisition. The different speed of learning at different jobs, that is, the experimentation component of learning, is a primary determinant of the timing of promotions and wage increases, which implies a much more convex wage growth at low tenures than when the speed of learning is the same at all jobs. Hence, the existing view that learning has only a negligible or insignificant impact on wages needs to be re-assessed.

My exercise contributes to a growing empirical literature (see especially Ferrall $(1997,2009)$ ), the goal of which is to shed light on the internal workings of firms and to bridge several areas of study. These areas include labor economics themes on the returns to firm tenure and labor market experience, industrial organization themes on the activities and boundaries of firms, personnel economics themes on the importance of firm strategies for hiring and retaining talented individuals (see Oyer and Shaefer (2011)), and, last, human resource management themes on the relationship between productivity and labor practices inside firms (see Bloom and Van Reenen (2011)). As for any structural model, the insights the model has offered should be subject to further verification. Yet overall, my findings attest to the potential of learning and human capital models, augmented along the dimensions considered, to capture salient features of careers.

baseline value at each prior, both experiments lead to even higher wage growth. 


\section{A Appendix}

This appendix contains omitted details of the model, the empirical specification, and the estimation results. See the Supplementary Appendix for any further detail. It is available online at https://sites.google.com/site/elenapastorino1econ/careers_supptot.pdf.

\section{A.1 Omitted Details about Equilibrium}

Best-Response Value Functions. Here I derive the best-response problem of a worker and of each firm. Given the strategies of all firms, at each state the worker's strategy satisfies the Bellman equation

$$
V^{w}\left(s_{t}, \boldsymbol{\varepsilon}_{t}, \cdot\right)=\max _{\mathbf{d}}\left\{\sum_{f=1}^{\mathbb{N}} d_{f}\left[(1-\delta) w_{f t}+\delta \eta_{f k_{f t}}\left(h_{t}\right) \int_{\varepsilon_{t+1}} E V^{w}\left(s_{t+1}, \varepsilon_{t+1}, \cdot \mid s_{t}, k_{f t}\right) d G\right]\right\}
$$

where $V^{w}\left(s_{t}, \boldsymbol{\varepsilon}_{t}, \cdot\right)=V^{w}\left(s_{t}, \boldsymbol{\varepsilon}_{t}, \mathbf{w}_{t}, \mathbf{k}_{t}\right), \mathbf{d}=\left(d_{1}, \ldots, d_{\mathbb{N}}\right)$ denotes the collection of the worker's possible acceptance $\left(d_{f}=1\right)$ or rejection $\left(d_{f}=0\right)$ decisions with respect to each firm $f$ 's offer of the wage $w_{f t}=w_{f}\left(s_{t}, \varepsilon_{t}\right)$ and the job $k_{f t}=k_{f}\left(s_{t}, \varepsilon_{t}\right)$, and $G$ is the c.d.f. of the future productivity shocks, $\varepsilon_{t+1}$. The expectation $E V^{w}$ is over the worker's performance realized at the end of the period, so conditional on $k_{f t}$, the beginning-of-period state next period is $s_{t+1}=\left(P_{f H k}\left(p_{t}\right), h_{t+1}\right)$ after high performance and $s_{t+1}=\left(P_{f L k}\left(p_{t}\right), h_{t+1}\right)$ after low performance. Note that, in evaluating employment offers, a worker trades the current wage against the value of the information and human capital that can be acquired at each firm and job.

Given the strategies of the other firms and the worker, at each state the strategy of any firm $f \in\{1, \ldots, \mathbb{N}\}$ solves the Bellman equation

$$
\begin{aligned}
\Pi^{f}\left(s_{t}, \varepsilon_{t}\right)=\max _{w, k} & \left(d_{f t}\left\{(1-\delta)\left[y_{f}\left(s_{t}, k\right)+\varepsilon_{f k t}-w\right]+\delta \eta_{f k}\left(h_{t}\right) \int_{\varepsilon_{t+1}} E \Pi^{f}\left(s_{t+1}, \varepsilon_{t+1} \mid s_{t}, k\right) d G\right\}\right. \\
& \left.+\sum_{g \neq f} d_{g t} \delta \eta_{g k_{g t}}\left(h_{t}\right) \int_{\varepsilon_{t+1}} E \Pi^{f}\left(s_{t+1}, \varepsilon_{t+1} \mid s_{t}, k_{g t}\right) d G\right),
\end{aligned}
$$

where $d_{f t}=d_{f}\left(s_{t}, \boldsymbol{\varepsilon}_{t}, \mathbf{w}_{t}, \mathbf{k}_{t}\right)$ and $d_{g t}=d_{g}\left(s_{t}, \boldsymbol{\varepsilon}_{t}, \mathbf{w}_{t}, \mathbf{k}_{t}\right)$ are the acceptance decisions of the worker with respect to firm f's and firm $g$ 's offers, $k_{g t}=k_{g}\left(s_{t}, \boldsymbol{\varepsilon}_{t}\right)$ is the job offered by firm $g$, and $E \Pi^{f}$ is the expectation over the worker's performance realized at the end of the period, conditional on the assigned job: job $k$ if firm $f$ employs the worker or job $k_{g t}$ if firm $g$ employs the worker. Note from the second term in (17) that in deciding which wage and offer to make, a firm takes into account the option value of not employing the worker in the current period and attracting him in some future period, after observing the worker's performance at competing firms and, possibly, once the firm can benefit from the human capital that the worker may have acquired there.

Match Surplus Value Function From No Employment/Separation. To understand how $w_{0}\left(s_{t}, \varepsilon_{t}\right)$ and $V^{A}\left(\cdot, f_{0 t}\right)$ are determined, let $f_{1 t}$ denote the firm offering the second-highest value of wages when firm $f_{0 t}$ employs the worker. Note that firm $f_{1 t}$ may or may not be firm $A$ - it is always firm $A$ if the labor market is a duopoly. In equilibrium $w_{0}\left(s_{t}, \boldsymbol{\varepsilon}_{t}\right)$ is the sum of two terms: the worker's one-period expected output at firm $f_{t} \in\left\{f_{0 t}, f_{1 t}\right\}, y_{f_{t}}\left(s_{t}, k_{f_{t} t}\right)+\varepsilon_{f_{t} t}$, and the term

$$
\Psi\left(s_{t}, k_{e_{t} t}\right)=\frac{\delta}{1-\delta} \int_{\varepsilon_{t+1}}\left[\eta_{f_{t}}\left(h_{t}\right) E V^{f_{t}}\left(\cdot \mid s_{t}, k_{f_{t} t}\right)-\eta_{e_{t} k_{e_{t} t}}\left(h_{t}\right) E \Pi^{f_{t}}\left(\cdot \mid s_{t}, k_{e_{t} t}\right)-\eta_{0 t}\left(h_{t}\right) E V^{w}\left(\cdot \mid s_{t}, k_{0 t}\right)\right] d G,
$$


which is the compensating wage differential between the offers of firm $f_{t}$ and the employing firm $e_{t}=\left\{A, f_{0 t}\right\}$ at state $\left(s_{t}, \varepsilon_{t}\right)$. In particular, if $e_{t}=A$, then $f_{t}=f_{0 t}$ whereas if $e_{t}=f_{0 t}$, then $f_{t}=f_{1 t}$. Formally, this component $\Psi\left(s_{t}, k_{e_{t}}\right)$ of $w_{0}\left(s_{t}, \boldsymbol{\varepsilon}_{t}\right)$ compensates the worker for any difference in information, human capital, and probability of exogenous separation between working today at firm $f_{t}$ and working today at firm $e_{t}$. Now, if $e_{t}=A$, then $f_{t}=f_{0 t}$ and $(1-\delta) w_{0}\left(s_{t}, \boldsymbol{\varepsilon}_{t}\right)$ equals

$$
(1-\delta)\left[y_{f_{0 t}}\left(s_{t}, k_{0 t}\right)+\varepsilon_{0 t}\right]+\delta \int_{\varepsilon_{t+1}}\left[\eta_{0 t}\left(h_{t}\right) E \Pi^{0}\left(\cdot \mid s_{t}, k_{0 t}\right)-\eta_{A k_{A t}}\left(h_{t}\right) E \Pi^{0}\left(\cdot \mid s_{t}, k_{A k_{A t}}\right)\right] d G,
$$

which implies $V^{w}\left(s_{t}, \varepsilon_{t}, f_{0 t}\right)$ can be expressed as

$\max _{f \neq A}\left\{\max _{k \in K^{f}}\left\{(1-\delta)\left[y_{f}\left(s_{t}, k\right)+\varepsilon_{f k t}\right]+\delta \eta_{f k}\left(h_{t}\right) \int E V^{f}\left(\cdot \mid s_{t}, k\right) d G\right\}-\delta \eta_{A k_{A t}}\left(h_{t}\right) \int E \Pi^{f}\left(\cdot \mid s_{t}, k_{A t}\right) d G\right\}$.

Hence, by definition of $V^{A}$ and the properties of extreme value distributions,

$$
\begin{gathered}
V^{A}\left(s_{t}, \varepsilon_{t}, f_{0 t}\right)=\ln \sum_{f \neq A, k \in K^{f}} \exp \left\{(1-\delta) y_{f}\left(s_{t}, k\right)+\delta \int_{\varepsilon_{t+1}}\left[\eta_{f k}\left(h_{t}\right) E V^{f}\left(\cdot \mid s_{t}, k\right)\right.\right. \\
\left.\left.-\eta_{A k_{A t}}\left(h_{t}\right) E \Pi^{f}\left(\cdot \mid s_{t}, k_{A t}\right)\right] d G\right\}+\delta \eta_{0 t}\left(h_{t}\right) \int_{\varepsilon_{t+1}} E \Pi^{A}\left(\cdot \mid s_{t}, k_{0 t}\right) d G+(1-\delta) \varepsilon_{0 t} .
\end{gathered}
$$

Suppose next that $e_{t}=f_{0 t}$, so $f_{t}=f_{1 t}$. Let $k_{1 t}$ denote the job offer of this firm, $\varepsilon_{1 t}$ the associated productivity shock, $1-\eta_{1 t}\left(h_{t}\right)$ the corresponding probability of exogenous separation, and $V^{1}$ firm $f_{1 t}$ 's match surplus value. Then, $(1-\delta) w_{0}\left(s_{t}, \boldsymbol{\varepsilon}_{t}\right)$ equals

$$
(1-\delta)\left[y_{f_{1 t}}\left(s_{t}, k_{1 t}\right)+\varepsilon_{1 t}\right]+\delta \int_{\varepsilon_{t+1}}\left[\eta_{1 t}\left(h_{t}\right) E V^{1}\left(\cdot \mid s_{t}, k_{1 t}\right)-\eta_{0 t}\left(h_{t}\right) E V^{1}\left(\cdot \mid s_{t}, k_{0 t}\right)\right] d G,
$$

which implies $V^{w}\left(s_{t}, \boldsymbol{\varepsilon}_{t}, f_{0 t}\right)$ can be expressed as

$$
\max _{f \neq f_{0 t}}\left\{\max _{k \in K^{f}}\left\{(1-\delta)\left[y_{f}\left(s_{t}, k\right)+\varepsilon_{f k t}\right]+\delta \eta_{f k}\left(h_{t}\right) \int E V^{f}\left(\cdot \mid s_{t}, k\right) d G\right\}-\delta \eta_{0 t}\left(h_{t}\right) \int E \Pi^{f}\left(\cdot \mid s_{t}, k_{0 t}\right) d G\right\} .
$$

Hence, by definition of $V^{A}$ and the properties of extreme value distributions,

$$
\begin{gathered}
V^{A}\left(s_{t}, \boldsymbol{\varepsilon}_{t}, f_{0 t}\right)=\ln \sum_{f \neq f_{0 t}, k \in K^{f}} \exp \left\{(1-\delta) y_{f}\left(s_{t}, k\right)+\delta \int_{\varepsilon_{t+1}}\left[\eta_{f k}\left(h_{t}\right) E V^{f}\left(\cdot \mid s_{t}, k\right)\right.\right. \\
\left.\left.-\eta_{0 t}\left(h_{t}\right) E \Pi^{f}\left(\cdot \mid s_{t}, k_{0 t}\right)\right] d G\right\}+\delta \eta_{0 t}\left(h_{t}\right) \int_{\varepsilon_{t+1}} E \Pi^{A}\left(\cdot \mid s_{t}, k_{0 t}\right) d G+(1-\delta) \varepsilon_{1 t} .
\end{gathered}
$$

From (18) and (19) it follows that firm $A$ 's match surplus value when it does not employ the worker, $V^{A}\left(s_{t}, \boldsymbol{\varepsilon}_{t}, f_{0 t}\right)$, can be expressed as $\varsigma_{0}\left(s_{t}, k_{A t}\right)+(1-\delta) \varepsilon_{0 t}$ if $e_{t}=A$ and $\varsigma_{0}\left(s_{t}, k_{0 t}\right)+(1-\delta) \varepsilon_{1 t}$ if $e_{t}=f_{0 t}$.

Under perfect competition, duopoly, and the oligopoly discussed in the context of the general model, the expression for $V^{A}\left(s_{t}, \varepsilon_{t}, f_{0 t}\right)$ simplifies considerably. Under perfect competition, $K^{f}=$ $K^{A}$ for all $f$ 's. Under duopoly, $V^{A}\left(s_{t}, \varepsilon_{t}\right)=V^{A}\left(s_{t}, \varepsilon_{t}, A\right)$, which is the value function of a standard single-agent dynamic discrete choice problem. (The proof of this result is in Pastorino and Kehoe (2012) for the case without human capital acquisition and without productivity or separation shocks. 
Adapting their proof to the current case is straightforward.) Under oligopoly, $K^{f} \neq K^{A}$ for $f \neq A$, $\mathbb{N}>1$, and each technology $f$ is adopted by at least one firm. In this case, the two expressions for $V^{A}\left(s_{t}, \varepsilon_{t}, f_{0 t}\right)$ reduce to

$$
\begin{gathered}
\max _{f \neq A, k \in K^{f}}\left\{(1-\delta)\left[y_{f}\left(s_{t}, k\right)+\varepsilon_{f k t}\right]+\delta \eta_{f k}\left(h_{t}\right) \int_{\varepsilon_{t+1}} E V^{A}\left(s_{t+1}, \varepsilon_{t+1} \mid s_{t}, k\right) d G\right\} \\
=\ln \sum_{f \neq A, k \in K^{f}} \exp \left\{(1-\delta) y_{f}\left(s_{t}, k\right)+\delta \eta_{f k}\left(h_{t}\right) \int_{\varepsilon_{t+1}} E V^{A}\left(\cdot \mid s_{t}, k\right) d G\right\}+(1-\delta) \varepsilon_{0 t}
\end{gathered}
$$

by the properties of type I extreme value distributions, where $\varepsilon_{0 t}$ is the productivity shock at the job offered by firm $f_{0 t}$. In (20), without loss, the maximization is intended over the jobs of firms with different technologies. Therefore, using (20) I obtain

$$
\begin{gathered}
V^{A}\left(s_{t}, \boldsymbol{\varepsilon}_{t}\right)=\max \left\{\max _{k \in K^{A}}\left\{(1-\delta)\left[y_{A}\left(s_{t}, k\right)+\varepsilon_{A k t}\right]+\delta \eta_{A k}\left(h_{t}\right) \int_{\varepsilon_{t+1}} E V^{A}\left(s_{t+1}, \varepsilon_{t+1} \mid s_{t}, k\right) d G\right\},\right. \\
\left.\ln \sum_{f \neq A, k \in K^{f}} \exp \left\{(1-\delta) y_{f}\left(s_{t}, k\right)+\delta \eta_{f k}\left(h_{t}\right) \int_{\varepsilon_{t+1}} E V^{A}\left(\cdot \mid s_{t}, k\right) d G\right\}+(1-\delta) \varepsilon_{0 t}\right\},
\end{gathered}
$$

as shown in Proposition 3 in the Supplementary Appendix. Note that $V^{A}\left(s_{t}, \boldsymbol{\varepsilon}_{t}, f_{0 t}\right)$ can also be expressed as $V^{A}\left(s_{t}, \boldsymbol{\varepsilon}_{t}, f_{0 t}\right)=\varsigma_{0}\left(s_{t}\right)+(1-\delta) \varepsilon_{0 t}$ where $\varsigma_{0}$ is a continuous function of $s_{t}$. In estimation I solve for (21) approximating $\varsigma_{0}$ with a polynomial in the prior with tenure-dependent coefficients; see Section A.2. When the deterministic component of the inner maximization problem in (21) systematically exceeds $\varsigma_{0}\left(s_{t}\right)$, then the market is nearly perfectly competitive or nearly a duopoly. The two market structures can be distinguished based on the relationship between average wages and output: the perfectly competitive case applies when wages (on average) equal expected output.

For all other market structures, (21) is an approximation, since (18) and (19) entail different expressions and they both affect $V^{A}$. The smaller $\Pi^{f}$ relative to $\Pi^{A}$, the better the approximation.

Note that the perfectly competitive case, the duopoly case, and the oligopoly case are naturally nested by the surplus value problem $V^{A}(\cdot)=\max \left\{V^{A}(\cdot, A), V^{A}\left(\cdot, f_{0 t}\right)\right\}$. In the perfectly competitive case, $V^{A}\left(\cdot, f_{0 t}\right)=V^{A}(\cdot, A)$. In the duopoly case $V^{A}\left(\cdot, f_{0 t}\right) \neq V^{A}(\cdot, A)$, but $V^{A}(\cdot)=V^{A}(\cdot, A)$. In the oligopoly case, $V^{A}\left(\cdot, f_{0 t}\right)$ is as in (20). By standard arguments (see Rust $(1987,1994)$ ), it is then possible to show that $V^{A}\left(s_{t}, \boldsymbol{\varepsilon}_{t}\right)=\max _{0 \leq k \leq K^{A}}\left\{v^{A}\left(s_{t}, k\right)+(1-\delta) \varepsilon_{k t}\right\}$, where $v^{A}\left(s_{t}, k\right)$ is the deterministic component of $V^{A}$ when firm $A$ employs the worker at job $k \in K^{A}$ and $v^{A}\left(s_{t}, 0\right)$ is the deterministic component of $V^{A}\left(\cdot, f_{0 t}\right)$. See Section A.2 and the Supplementary Appendix.

\section{A.2 Empirical Analysis}

Here I provide details about the empirical specification of the model in terms of the parameters for output and human capital, exogenous separations, performance ratings, and wages. I also provide further details about identification, outline the solution of the match surplus value problem, and present evidence about model fit and specification based on Pearson's $\chi^{2}$ test.

Model Parameterization. Altogether, the model has 75 estimated parameters: 38 parameters for the distribution of the initial prior, output, human capital, and performance ratings, and 37 parameters for wages.

1. Output and Human Capital. In estimation I set the parameters of output and human capital at the second-best firm to zero. Hence, the parameters $b_{k t}\left(k_{t-1}\right)$ and $c_{k t}$ are to be interpreted as 
differences between the values of these parameters at my firm and at the second-best firm. Whenever any of these parameters is zero, such a parameter is to be interpreted to be the same across my firm and the second-best firm. Recall that the data do not contain any direct measures of output and that, in contrast to models of perfect competition, in my model wages are not informative about output at my firm but rather at the second-best firm. Thus, output and human capital parameters are identified by managers' transitions across the three job levels at my firm and by separations - in fact, primarily by transitions across the firm's levels, given that in the data separations from any level are approximately constant in tenure and not very sensitive to performance.

Note that the number of possible transitions across levels proliferates rapidly as tenure increases but there are few observations for many of these transitions. So, it is not possible to estimate the associated parameters with any precision. In order to limit parameter proliferation, I proceed as follows. I parameterize $b_{k t}\left(k_{t-1}\right)$ at each level as a piecewise function of tenure,

$$
b_{k t}\left(k_{t-1}\right)=\gamma_{k}\left(k_{t-1}\right) t I(t<4)+\gamma_{k t}\left(k_{t-1}\right) I(4 \leq t \leq 7) \text {. }
$$

In the case of transitions with either zero or relatively few observations, I did not estimate any parameter of (22) and normalized the relevant parameters to zero. For transitions with approximately the same number of observations, I maintained that the associated parameters are identical. In particular, since in the data job transitions are by one level, I allowed $b_{k t}\left(k_{t-1}\right)$ to be nonzero only when $k$ and $k_{t-1}$ are within one level. So, I set $b_{1 t}(L 3)=b_{3 t}(L 1)=0$ in all tenures. Next, note that for any $k_{t-1}$, the parameters $b_{k t}\left(k_{t-1}\right)$ are identified by managers' transitions across the three levels at firm $A$. Hence, a further normalization is needed. For convenience of interpretation, I set $b_{2 t}\left(k_{t-1}\right)=0$ in all tenures and consider Level 2 as the reference level. (An alterative could be to impose a form of symmetry across parameters, for instance, by assuming $b_{k^{\prime} t}(k)=b_{k t}\left(k^{\prime}\right)$. Such a restriction, however, is highly rejected by the data, since all promotions are by one level and demotions never occur. That is, transitions are strongly one-sided.) These criteria have led to the following parameterization at each level. At Level 1, since all managers are assigned at entry to Level 1 , I normalized $b_{11}$ at 1,000. The combination of rapid promotions to Level 2 and high separation rates in each tenure implies that there are few observations at Level 1 in higher tenures. Thus, I set $b_{1 t}(L 1)$ at zero for $t \geq 2$. Based on the above criteria, I also set $b_{15}(L 2)=b_{16}(L 2)=b_{17}(L 2)$ and estimated $b_{14}(L 2)$ and $b_{15}(L 2)$ (as differences from the corresponding $b_{1 t}(L 1)$ ). At Level 2, I estimated no $b_{k t}$ parameter, as mentioned. At Level 3 , I set $b_{35}(L 3)=b_{36}(L 3)$ and estimated $b_{34}(L 3), b_{35}(L 3)$, and $b_{37}(L 3)$ (as differences from the corresponding $\left.b_{3 t}(L 2)\right){ }^{27}$

Similarly, as for the slope parameters $c_{k t}$ of expected output, I did not estimate any parameters at level and tenure combinations with zero or relatively few observations, and normalized them to zero. Also, for parameters at level and tenure combinations with the same number of observations, I maintained they are identical. Formally, at Level 1 I specified

$$
c_{1 t}=c_{12} \sum_{\tau=2}^{3} I(t=\tau)+c_{14} \sum_{\tau=4}^{8} I(t=\tau)
$$

in light of the different patterns of promotions out of Level 1 from the fourth year of tenure on. Given the small number of observations at Level 1 in high tenures, I only estimated $c_{12}$. At Level 2 , I estimated the parameters $c_{22}, c_{23}, c_{25}$, and $c_{26}$, and set $c_{22}=c_{24}$, and $c_{26}=c_{27}$. Given that no

\footnotetext{
${ }^{27}$ The reason is that the model can account for transitions from Level 2 to 3 in two ways: either through newly promoted managers from Level 2 to 3 having high output intercept at Level $3\left(b_{3 t}(L 2)\right)$ or through managers having high output intercept at Level 3 once they have been at Level 3 for at least one period $\left(b_{3 t}(L 3)\right)$. Hence, only the difference in these parameters can be precisely pinned down. If, for instance, there was variation in the data in the level from which managers are promoted into Level 3, these parameters could be estimated precisely.
} 
manager is assigned to Level 2 at entry and only a small fraction of managers are assigned to Level 2 in the eighth year of tenure, I set both $c_{21}$ and $c_{28}$ at zero.

At Level 3, since no manager is observed at this level until the third year of tenure, I restricted $c_{31}=c_{32}=c_{33}$. Given that the hazard rates of promotion from Level 1 to 2 and from Level 2 to 3 display similar qualitative features from $t \geq 2$ on, I allowed for common components across the parameters $c_{2 t}$ and $c_{3 t}$ at $t \geq 2$ to conserve on parameters. In particular, I specified $c_{3 t}=\underline{c}_{3 t}+c_{22}$ at $t \geq 4$. The choice of $c_{22}$ as the 'benchmark' parameter at Level 2 is due to the high separation rate from Level 2 and the high promotion rate from Level 2 to 3 in each tenure: output parameters of Level 2 in low tenures can be more precisely pinned down. This formulation has led to $c_{35}=$ $c_{36}=c_{22}$. In sum, at Level 3 I just estimated the parameters $c_{31}, c_{34}, c_{37}$, and $c_{38}$.

2. Exogenous Separations. I specify the probability of exogenous separation to depend on a manager's tenure in the firm and current level assignment, so $\eta_{k t}=\eta_{k}\left(h_{t}\right)$. I allow only for variation in $\eta_{k t}$ across levels and tenures that proves statistically significant, whenever setting these parameters equal across levels or tenures does not affect any other parameter estimate. As a result, the parameters of the probability of a separation shock, respectively, at Levels 1, 2, and 3 are: (1) at the end of period 1: $\eta_{11}, \eta_{21}$, and $\eta_{31} ;(2)$ at the end of period 2 : none, since $\eta_{12}=\eta_{11}, \eta_{22}=\eta_{21}$, and $\eta_{32}=\eta_{31} ;(3)$ at the end of period $3: \xi_{3}$, since $\eta_{13}=\eta_{14}+\xi_{3}, \eta_{23}=\eta_{22}+\xi_{3}$, and $\eta_{33}=\eta_{32}$; (4) at the end of period 4: $\eta_{14}$ and $\eta_{24}$, since $\eta_{34}=\eta_{24}$; (5) at the end of period 5: $\eta_{25}$, since $\eta_{15}=\eta_{14}$ and $\eta_{35}=\eta_{25}$; (6) at the end of period $6: \eta_{26}$, since $\eta_{16}=\eta_{15}$ and $\eta_{36}=\eta_{26}$; (7) at the end of period 7: $\eta_{27}$, since $\eta_{17}=\eta_{16}$ and $\eta_{37}=\eta_{27}$; and (8) at the end of period 8 and onward: none, since $\eta_{1 t}=\eta_{17}, \eta_{2 t}=\eta_{27}$, and $\eta_{3 t}=\eta_{2 t}, t \geq 8$. For simplicity, I refer to these parameters as $\eta_{18}, \eta_{28}$, and $\eta_{38}$. So, the separation shock parameters I estimate are $\left(\eta_{11}, \xi_{3}, \eta_{14}\right)$ for Level 1 , $\left(\eta_{21}, \eta_{24}, \eta_{25}, \eta_{26}, \eta_{27}\right)$ for Level 2 , and $\eta_{31}$ for Level 3 .

3. Performance Ratings. Recall that I interpret a rating of 1 at Level $k$ in the data as corresponding to the realization of high performance, $y_{A H k}\left(h_{t}, i\right)$, and a rating of 0 as corresponding to the realization of low performance, $y_{A L k}\left(h_{t}, i\right)$. As do BGH, I assume that, even if a manager is part of a team, through the observation of various aspects of the production process, the evaluator of the manager is able to determine the manager's contribution to final output. For instance, through conversations with team members and co-workers, the evaluator can infer how well a particular manager performed his job. I also maintain that the evaluator has available sufficient information to separate, on the basis of realized output, $y_{A j k}\left(h_{t}\right)+\varepsilon_{A k t}, j=H, L$, the manager's performance, $y_{A j k}\left(h_{t}\right)$, from the idiosyncratic productivity shock, $\varepsilon_{A k t}$. For example, in the context of a bank, the evaluator understands when the value of the portfolio of loans of a particular loan manager has increased in a year simply due to the fact that companies under his responsibility have experienced an unusually positive return in the year, which is unrelated to the manager's ability.

Based on Keane and Wolpin (1997) and Keane and Sauer (2009), I allow for error in recorded performance ratings as follows. Let $E_{0}\left(L_{t}^{o}, t\right)=\operatorname{Pr}\left(R_{t}^{o}=1 \mid R_{t}=0, L_{t}^{o}, t\right)$ denote the probability of a recorded high rating, $R_{t}^{o}=1$, when a low rating is realized, $R_{t}=0$, at level $L_{t}^{o}$ in tenure $t$. Let $E_{1}\left(L_{t}^{o}, t\right)=\operatorname{Pr}\left(R_{t}^{o}=0 \mid R_{t}=1, L_{t}^{o}, t\right)$ denote the probability of a recorded low rating when a high rating is realized at level $L_{t}^{o}$ in tenure $t$. I specify $E_{0}\left(L_{t}^{o}, t\right)$ and $E_{1}\left(L_{t}^{o}, t\right)$ as

$$
\begin{gathered}
E_{0}\left(L_{t}^{o}, t\right)=\frac{\exp \left\{d_{0}+d_{2}\left(L_{t}^{o}\right)\left[t I\left(L_{t}^{o}=1\right)+(t-1) I\left(L_{t}^{o}=2\right)\right]\right\}}{1+\exp \left\{d_{0}+d_{2}\left(L_{t}^{o}\right)\left[t I\left(L_{t}^{o}=1\right)+(t-1) I\left(L_{t}^{o}=2\right)\right]\right\}}, \\
E_{1}\left(L_{t}^{o}, t\right)=\frac{1}{1+\exp \left\{d_{0}+d_{1}+d_{2}\left(L_{t}^{o}\right)\left[t I\left(L_{t}^{o}=1\right)+(t-1) I\left(L_{t}^{o}=2\right)\right]\right\}} .
\end{gathered}
$$

I let these errors vary both with a manager's assigned level, since the evaluation of performance 
is often job-specific, and with a manager's tenure in the firm, to capture the possibility that performance appraisal may be conducted more thoroughly at certain stages in a manager's career at the firm, such as when managers are newly hired or become eligible for new tasks. Since no individual is observed at Level 2 at entry, I allow the errors at Level 2 to depend on $t-1$ rather than $t$. Note that the monotonicity condition required for the identification of the classification error rates corresponds to the restriction that the probability of a reported high rating increases with the probability of a true high rating or, equivalently, $d_{1}>0$, which is satisfied by my estimates. See Hausman, Abrevaya, and Scott-Morton (1998).

To limit parameter proliferation, and based on model diagnostic and fit, in (23) and (24) I maintain that $d_{1}=d_{0}$. Also, I estimate classification error parameters only at Levels 1 and 2 because among managers assigned to Level 3, many ratings are missing. Specifically, ratings are missing for no fewer than 35 percent of individuals assigned to (the original) Level 3 and higher, with much higher proportions of missing values, up to 44.9 percent, in lower tenures. Moreover, the distribution of ratings at Level 3 and higher in the data differs from the distribution at lower levels. Estimation of classification error rates at Level 3 thus proved problematic. As a result, the estimated parameters governing the distribution of performance ratings are $\left(\left\{\alpha_{k}, \beta_{k}\right\}_{k=1}^{3}, d_{0}, d_{2}(L 1), d_{2}(L 2)\right)$. In this specification, the greater is $d_{2}(L 1)$ or $d_{2}(L 2)$, the greater is the persistence in misreporting. Since the probability of a recorded rating is not a linear function of its true probability, this classification error scheme leads to bias (Keane and Sauer (2009)). This feature accommodates the fact that a potentially important source of error in recorded ratings is the tendency of supervisors to assign uniform ratings to employees regardless of their actual performance, which may lead to systematic misreporting of actual performance. This tendency is well known and has been discussed by Baker, Jensen, and Murphy (1988), Murphy (1992), and Prendergast (1999), among others.

4. Wages. I set the coefficients $\varpi_{1 k}, \varpi_{2 k}$, and $\varpi_{3 k}$, respectively, on age, age $e^{2}$, and edu, equal at Levels 1 and 2 . I denote their common value by $\varpi_{1}, \varpi_{2}$, and $\varpi_{3}$. As for the coefficients on the yearof-entry dummies, I also set $\varpi_{y m}=0$ for $0 \leq m \leq 3$ and $\varpi_{y 4}=\varpi_{y 5}$, so that estimated parameters for the year-of-entry dummies are $\left\{\varpi_{y m}\right\}_{m=5}^{9}$. As for the remaining coefficients, I assume that the coefficient on tenure at Level 1 is $\omega_{1 t}=\omega_{12} I(t<5)+\omega_{15} I(t \geq 5)$ with $\omega_{15}=-\omega_{12}$, to account for the progressively greater proportion of managers at Level 1 who are paid relatively low wages from the fifth tenure year on. Finally, I assume that the standard error of the shock to (log) wages does not vary across skill types at Level 3 . So, the estimated wage parameters are $\left\{\omega_{0 i 1}, \omega_{0 i 2}, \omega_{0 i 3}\right\}_{i=1}^{4}$, $\varpi_{1}, \varpi_{2}, \varpi_{3}, \varpi_{13}, \varpi_{23}, \varpi_{33}, \omega_{12},\left\{\varpi_{y m}\right\}_{m=5}^{9},\left\{\omega_{2 i}\right\}_{i=1}^{4},\left\{\sigma_{1 k}, \sigma_{2 k}, \sigma_{3 k}, \sigma_{4 k}\right\}_{k=1}^{2}$, and $\sigma_{3}$.

Identification. I discuss here how the degree of transferability of acquired human capital across levels of my firm and the degree of transferability of unobserved and acquired human capital across firms can be detected in my data.

1. Transferability of Acquired Human Capital Across Levels of My Firm. A crucial feature of the data that helps me pin down the transferability of human capital acquired at the firm across levels is the variation of the hazard rate of promotion with tenure and performance. To see why, recall (11) and suppose that tenure in the firm or in a given level makes a manager more productive at that level but not at any other level. This task-specific property of acquired human capital would imply that the probability of promotion of a manager out of a level decreases with tenure, regardless of the number of past high ratings, as the greater task-specific human capital a manager acquires makes the manager better suited to the current level. Suppose, instead, that tenure in the firm or in a level substantially improves a manager's expected output at higher levels. In this case, regardless of the number of past high ratings, the probability of promotion out of a level can increase with tenure in the firm or in a level. Moreover, even after several low ratings, managers may not be demoted to a lower level. Hence, the tenure profile of the hazard rate of promotion 
at each level for different histories of level assignments and performance ratings provides a set of moments that help identify the degree of transferability of human capital across levels.

2. Transferability of Unobserved Ability and Acquired Human Capital Across Firms. The variability of wages with performance is the key piece of information in the data that helps identify the extent to which unobserved ability is transferable across firms. To see why, note first that the fact that managers with higher performance receive higher wages supports the idea that unobserved ability is transferable across firms. Therefore, at each level the strength of the dependence of average wages on past performance helps identify the degree of transferability of unobserved ability across firms. In estimation, this dependence is reflected in the positive estimated coefficient on the prior in the wage equation.

Next, recall that the transferability across firms of the human capital acquired before entry into my firm is formally captured by the dependence of wages on managers' entry characteristics, since $h_{1}=($ age $, e d u, y e a r)$. The variability of wages with tenure and previous period assignment is, instead, the key piece of information that helps identify the extent to which human capital acquired at my firm is transferable to other firms. For concreteness, suppose that acquired human capital were close to general across firms. Then, for any given number of past high ratings, by (15) average wages would increase with tenure and previous period assignment. Thus, the dependence of average wages on tenure and previous period level assignment, for varying sequences of realized high ratings, provides a set of moments that identify the degree of transferability to other firms of the human capital acquired at my firm. In estimation, only the effect of a manager's tenure, and only at Level 1, has proved somehow important. These results suggest a low degree of transferability to other firms of the human capital acquired at my firm.

Job Assignment and Turnover. Recall the specification of expected output at firm $A$. Let $k=0$ denote the event in which a manager is not employed by the firm. By applying the results of Rust $(1987,1994)$ and assuming that each productivity shock has variance $\pi^{2} / 6$, it follows

$$
V^{A}\left(p_{i t}, t-1, k_{t-1}, \varepsilon_{t}\right)=\max _{0 \leq k \leq 3}\left\{v^{A}\left(p_{i t}, t-1, k_{t-1}, k\right)+(1-\delta) \varepsilon_{k t}\right\}
$$

where $v^{A}\left(p_{i t}, t-1, k_{t-1}, k\right)$, for $1 \leq k \leq 3$ and $2 \leq t \leq 7$, is given by

$$
\begin{gathered}
(1-\delta) y_{A}\left(p_{i t}, t-1, k_{t-1}, k\right)+\delta \eta_{k t}\left[\alpha_{k} p_{i t}+\beta_{k}\left(1-p_{i t}\right)\right] \ln \sum_{0 \leq k^{\prime} \leq 3} \exp \left[v^{A}\left(P_{H k}\left(p_{i t}\right), t, k, k^{\prime}\right)\right] \\
+\delta \eta_{k t}\left[1-\alpha_{k} p_{i t}-\beta_{k}\left(1-p_{i t}\right)\right] \ln \sum_{0 \leq k^{\prime} \leq 3} \exp \left[v^{A}\left(P_{L k}\left(p_{i t}\right), t, k, k^{\prime}\right)\right] .
\end{gathered}
$$

Here $v^{A}\left(P_{j k}\left(p_{i t}\right), t, k, k^{\prime}\right), j=H, L$, incorporates the law of motion for $p_{i t}$ and $h_{t}$ conditional on the assignment to Level $k$ in tenure $t$. Similar expressions can be obtained for $t=1$ and $t=8$. See the Supplementary Appendix.

The model implies that the match surplus value of firm $A$ when $k=0$ is a continuous function of the prior. Given the lack of direct information in my data on other firms, I specify this continuous function as a flexible polynomial in $p_{i t}$. (See Erdem and Keane (1996) and Ching (2010) for similar parameterizations of the value of the reference alternative in learning models of dynamic discrete choice.) The terms of degree zero and one of this polynomial are, respectively, intended to be subsumed in $b_{k t}\left(k_{t-1}\right)$ and $c_{k t}$ : they cannot be separately identified, respectively, from $b_{k t}\left(k_{t-1}\right)$ and $c_{k t}$. As mentioned, I set them at zero in estimation and interpret $b_{k t}\left(k_{t-1}\right)$ and $c_{k t}$ as differences with respect to the corresponding parameters of the second-best firm. In estimation, the terms of degree higher than one of this polynomial have proved impossible to estimate with any precision 
due to the fact that, conditional on tenure, $v^{A}$ has not exhibited sufficient curvature in the prior at all trial sets of parameter values. So, I ignored them. The probabilities of assignment to Level $k$, $0 \leq k \leq 3$, in each tenure can be easily computed. See the Supplementary Appendix.

Model Fit. In assessing model fit and conducting the counterfactual experiments, I simulated 4,000 prior realizations per manager, drawn from the estimated nonparametric distribution of initial priors. Table 1 shows that the model tracks remarkably well, qualitatively and quantitatively, the profiles of assignment of managers to Levels 1, 2, and 3, which are nonlinear and nonmonotone in tenure, as well as the tenure pattern of manager separation. Table 2 shows that the model accurately reproduces the feature that outflows from Levels 1 and 2 come from an essentially constant hazard rate of separation and a hazard of promotion that is first increasing, then decreasing with tenure. As Table 3 shows, the model also successfully fits the patterns of performance ratings both at Level 1 (with slight overpredictions in the third and fifth years of tenure) and at Level 2 (except for some discrepancies in the fourth year of tenure). Lastly, Table 4 shows that the model reproduces quite well the distribution of wages at each level and tenure, except for slight discrepancies at Level 3 in the highest tenures. The largest such discrepancies are at Level 3 in the sixth and seventh years of tenure, but this difference is partly due to the high rate of attrition in the sample. Indeed, the fit of the model to the wage data based on the larger sample is substantially better. See the Supplementary Appendix.

One criterion to formally evaluate model fit is the Pearson's $\chi^{2}$ goodness-of-fit test. I perform this test based on the statistic $s \sum_{j=1}^{J}\left\{[g(j)-g(j)]^{2} / g(j)\right\}$, where $g(\cdot)$ indicates the empirical density function of a given endogenous variable, $g(\cdot)$ denotes the maximum likelihood estimate of the density function of that variable, $s$ indicates the number of observations, and $J$ the number of categories considered (not taking into account the fact that the parameters of the model are estimated). I compare observed and predicted outcomes in terms of the distribution of managers across levels in each of the first seven years of tenure, the distribution of performance ratings at Levels 1 and 2 in each such year of tenure, and the distribution of wages at each level and in each such year of tenure.

The results of the test are as follows. In terms of the distribution of managers across Levels 0 (separation) through 3 in each tenure, the $\chi^{2}$ goodness-of-fit test does not reject the model at conventional significance levels in any tenure. In terms of the hazard rates of separation, retention at a level, and promotion at each level and tenure, the test does not reject the model at conventional significance levels, apart from the second, third, fourth, and sixth years of tenure at Level 1 and the second and third years of tenure at Level 2. However, in this case the outcome of the test is arguably very much influenced by the small number of observations at Levels 1 and 2 in high tenures. In terms of the distribution of performance ratings at Levels 1 and 2 in each tenure, the test does not reject the model at conventional significance levels in any tenure. Finally, as for the distribution of wages at Levels 1, 2, and 3 in each tenure, the test does not reject the model at conventional significance levels, apart from the third year of tenure at Level 2 and the fourth, fifth, sixth, and seventh years of tenure at Level 3. An issue in interpreting these results for wages may be the large attrition in the sample, which implies that only a fraction of observations are on managers at Level 3 in high tenures relative to the size of observations on managers in the first year. See the estimates on the larger sample for improved fit.

The Role of Persistent Uncertainty. In the fast learning at Level 2 case, jobs at Level 2 are made to be nearly perfectly informative about ability, with $\alpha_{2}=0.99$ and $\beta_{2}=0.01$, whereas the other parameters are fixed at their baseline values. Similarly, fast learning at Level 2 yields higher wage growth, much larger wage dispersion at Level 2, and faster promotions. Perhaps surprisingly, it also 
leads to a lower percentage of managers assigned to Level 3 in high tenures and much lower wage dispersion at Level 3 relative to the baseline model. The reason is that increasing $\alpha_{2}$ and decreasing $\beta_{2}$ makes Level 2 more attractive for managers with high priors, who tend to be managers with high tenures in the firm. In turn, since managers reach Level 3 at lower priors than in the baseline case, the standard deviation of wages at Level 3 is much lower than at Level 2 (and lower than in the baseline model).

\section{References}

Bagger, J., F. Fontaine, F. Postel-Vinay, and J.-M. Robin (2011): "Tenure, Experience, Human Capital, and Wages: A Tractable Equilibrium Search Model of Wage Dynamics", mimeo.

Baker, G., M. Gibbs, and B. Holmström (1994a): "The Internal Economics of the Firm: Evidence from Personnel Data," Quarterly Journal of Economics 109(4), 881-919.

- (1994b): "The Wage Policy of a Firm," Quarterly Journal of Economics 109(4), 921-955.

Baker, G., M.C. Jensen, and K.J. Murphy (1988): "Compensation and Incentives: Practice vs. Theory," Journal of Finance 48(3), 593-616.

Belzil, C., and B. Bognanno (2008): "Promotions, Demotions, Halo Effects, and the Earnings Dynamics of American Executives," Journal of Labor Economics 26(2), 287-310.

Bergemann, D., and J. Välimäki (1996): "Learning and Strategic Pricing," Econometrica 64(5), 1125-1149.

Berkovec, J., and S. Stern (1991): “Job Exit of Older Men," Econometrica 59(1), 189-210.

Bernhardt, D. (1995): "Strategic Promotion and Compensation," Review of Economic Studies 62(2), 315-339.

Bernhardt, D., and D. Scoones (1993): "Promotion, Turnover, and Preemptive Wage Offers," American Economic Review 83(4), 771-791.

Blackwell, D. (1951): "Comparison of Experiments," J. Neyman, Ed., Proceedings of the Second Berkeley Symposium on Mathematical Statistics and Probability, University of California Press.

Bloom, N., and J. Van Reenen (2011): "Human Resource Management and Productivity," in Handbook of Labor Economics, Volume IVb, O. Ashenfelter and D. Card, Eds., Amsterdam: North-Holland, 1697-1767.

Buchinsky, M., D. Fougère, F. Kramarz, and R. Tchernis (2010): "Interfirm Mobility, Wages, and the Returns to Seniority and Experience in the United States," Review of Economic Studies 77(3), 972-1001.

Chiappori, P.-A., B. Salanié, and J. Valentin (1999): "Early Starters versus Late Beginners," Journal of Political Economy 107(4), 731-760.

Ching, A.T. (2010): "A Dynamic Oligopoly Structural Model for the Prescription Drug Market after Patent Expiration", International Economic Review 51(4), 1175-1207.

Ching, A.T., T. Erdem, and M.P. Keane (2011): "Learning Models: An Assessment of Progress, Challenges and New Developments," mimeo.

Crawford, G.S., and M. Shum (2005): "Uncertainty and Learning in Pharmaceutical Demand," Econometrica 73(4), 1137-1173.

Davis, S. (1997): "Sorting, Learning, and Mobility When Jobs Have Scarcity Value: A Comment," Carnegie-Rochester Conference Series on Public Policy 46(1), 327-337.

DeVaro, J., and M. Waldman (2012): "The Signaling Role of Promotions: Further Theory and 
Empirical Evidence," Journal of Labor Economics 30(1), 91-147.

Eckstein, Z., and K.I. Wolpin (1999): "Why Youths Drop Out of High School: The Impact of Preferences, Opportunities, and Abilities," Econometrica 67(6), 1295-1339.

Erdem, T., and M.P. Keane (1996): "Decision-making Under Uncertainty: Capturing Dynamic Brand Choice Processes in Turbulent Consumer Goods Markets", Marketing Science 15(1), 1-20.

Farber, H.S., and R. Gibbons (1996): "Learning and Wage Dynamics," Quarterly Journal of Economics 111(4), 1007-1047.

Felli, L., and C. Harris (2004): "Firm-Specific Training", STICERD Theoretical Economics, Discussion Paper No. TE/04/473.

Felli, L., and C. Harris (1996): "Learning, Wage Dynamics, and Firm-Specific Human Capital", Journal of Political Economy 104(4), 838-868.

Ferrall, C. (1997): "Empirical Analysis of Occupational Hierarchies", Journal of Human Resources $32(1), 1-34$.

Ferrall, C., K.G. Salvanes, and E.Ø. Sørensen (2009): "Wages and Seniority When Coworkers Matter: Estimating a Joint Production Economy Using Norwegian Administrative Data", QED Working Paper 1200.

Flinn, C.J. (1986): "Wages and Job Mobility of Young Workers," Journal of Political Economy $94(3), 88-110$.

Ghosh, S. (2007): "Job Mobility and Careers in Firms", Labour Economics 14 (3), 603-621.

Gibbons, R., L.F. Katz, T. Lemieux, and D. Parent (2005): "Comparative Advantage, Learning, and Sectoral Wage Determination", Journal of Labor Economics 23(4), 681-724.

Gibbons, R., and M. Waldman (1999a): "Careers in Organizations: Theory and Evidence," in Handbook of Labor Economics, Volume IIIB, O. Ashenfelter and D. Card Eds., Amsterdam: North-Holland, 2373-2437.

- (1999b): "A Theory of Wage and Promotion Dynamics Inside Firms," Quarterly Journal of Economics 114(4), 1321-1358.

- (2006): "Enriching a Theory of Wage and Promotion Dynamics Inside Firms," Journal of Labor Economics 24(1), 59-107.

Greenwald, B. (1986): "Adverse Selection in the Labour Market," Review of Economic Studies 53(3), 325-347.

Groes, F., P. Kircher, and I. Manovskii (2010): "The U-Shapes of Occupational Mobility", mimeo.

Harris, M., and B. Holmström (1982): "A Theory of Wage Dynamics," Review of Economic Studies 49(3), 315-333.

Hausman, J.A., J. Abrevaya, and F.M. Scott-Morton (1998): "Misclassification of the Dependent Variable in a Discrete-Response Setting," Journal of Econometrics 87(2), 239-269.

Heckman, J.J., and B. Singer (1984): "A Method for Minimizing the Impact of Distributional Assumptions in Econometric Models for Duration Data," Econometrica 52(2), 271-320.

Hoderlein, S., J. Klemelä, and E. Mammen (2010): "Analyzing the Random Coefficient Model Nonparametrically," Econometric Theory 26(3), 804-837.

Holmström, B., and J. Tirole (1989): "The Theory of the Firm," in Handbook of Industrial Organization, Volume I, R. Schmalensee and R. Willig Eds., Amsterdam: North-Holland, 61-133.

Hu, Y., and M. Shum (2012): "Nonparametric Identification of Dynamic Models with Unobserved State Variables," mimeo, Johns Hopkins University, forthcoming, Journal of Econometrics. Hunnes, A. (2012): "Testing the Role of Comparative Advantage and Learning in Wage and 
Promotion Dynamics", International Journal of Manpower 33(5), 556-582.

Jovanovic, B. (1979): "Job Matching and the Theory of Turnover," Journal of Political Economy 87(5), 972-990.

Jovanovic, B., and Y. Nyarko (1997): "Stepping-stone Mobility," Carnegie-Rochester Conference Series on Public Policy 46(1), 289-325.

Khan, L. and F. Lange (2011): "Employer Learning, Productivity and the Earnings Distribution: Evidence from Performance Measures", mimeo.

Kasahara, H., and K. Shimotsu (2009): "Nonparametric Identification of Finite Mixture Models of Dynamic Discrete Choices," Econometrica 77(1), 135-175.

Keane, M.P., and R.M. Sauer (2009): "Classification Error in Dynamic Discrete Choice Models: Implications for Female Labor Supply Behavior," Econometrica 77(3), 975-991.

Keane, M.P., and K.I. Wolpin (1997): "The Career Decisions of Young Men," Journal of Political Economy 105(3), 473-522.

Kremer, M. (1993): "The O-ring Theory of Economic Development," Quarterly Journal of Economics 108(3), 551-575.

Kremer, M., and E. Maskin (1996): "Wage Inequality and Segregation by Skill," NBER Working Paper 5718.

Lazear, E. (1992): "The Job as a Concept," in Performance Measurement, Evaluations, and Incentives, W. Bruns Eds., Boston: Harvard University Press, 183-215.

Lluis, S. (2005): "The Role of Comparative Advantage and Learning in Wage Dynamics and Intrafirm Mobility: Evidence from Germany", Journal of Labor Economics 23(4), 725-767.

MacDonald, G. (1982): "A Market Equilibrium Theory of Job Assignment and Sequential Accumulation of Information", American Economic Review 72(5), 1038-1055.

Magnac, T., and D. Thesmar (2002): "Identifying Dynamic Discrete Decision Processes," Econometrica 70(2), 801-816.

Miller, R.A. (1984): "Job Matching and Occupational Choice," Journal of Political Economy 92(6), 1086-1120.

Murphy, K.J. (1992): "Performance Measurement and Appraisal: Motivating Managers to Identify and Reward Performance," in Performance Measurement, Evaluations, and Incentives, W. Bruns Eds., Boston: Harvard University Press, 37-62.

Nagypál, É. (2007): "Learning by Doing vs. Learning About Match Quality: Can We Tell Them Apart?" Review of Economic Studies 74(2), 537-566.

Oyer, P., and S. Shaefer (2011): "Personnel Economics: Hiring and Incentives," in Handbook of Labor Economics, Volume IVb, O. Ashenfelter and D. Card, Eds., Amsterdam: North-Holland, 1769-1823.

Papageorgiou, T. (2012): "Learning Your Comparative Advantage", mimeo.

Pastorino, E. (2013): "Job Matching Within and Across Firms", mimeo.

Pastorino, E., and P.J. Kehoe (2012): "Efficiency and Pricing in Markets with Experience Goods", mimeo.

Prendergast, C. (1999): "The Provision of Incentives in Firms," Journal of Economic Literature 37(1), 7-63.

Prescott, E. C., and M. Visscher (1980): "Organization Capital," Journal of Political Economy 88(3), 446-461.

Ricart i Costa, J. (1988): "Managerial Task Assignment and Promotions," Econometrica 56(2), $449-466$. 
Rosen, S. (1982): "Authority, Control, and the Distribution of Earnings," Bell Journal of Economics $13(2), 311-323$.

Rubinstein, Y., and Y. Weiss (2007): "Post Schooling Wage Growth: Investment, Search and Learning", in Handbook of the Economics of Education, Volume I, E.A. Hanushek and F. Welch Eds., Amsterdam: North-Holland, 1-67.

Rust, J. (1987): "Optimal Replacement of GMC Bus Engines: An Empirical Model of Harold Zurcher," Econometrica 55(5), 999-1033.

- (1994): "Structural Estimation of Markov Decision Processes," in Handbook of Econometrics, Volume IV, R. Engle and D. McFadden, Eds., Amsterdam: North-Holland, 3081-3143.

Sanders, C., and C. Taber (2012): "Life-Cycle Wage Growth and Heterogeneous Human Capital", Annual Review of Economics 4, 399-425.

Sauer, R.M. (1998): "Job Mobility and the Market for Lawyers," Journal of Political Economy 106(1), 147-171.

Thomas, J.P., and T. Worrall (1988): "Self-enforcing Wage Contracts," Review of Economic Studies 55(4), 541-54

Thomas, J.P., and T. Worrall (2007): "Limited Commitment Models Of The Labour Market," Scottish Journal of Political Economy 54(5), 750-773.

Topel, R. (1991): "Specific Capital, Mobility, and Wages: Wages Raise with Job Seniority," Journal of Political Economy 99(1), 145-176.

Waldman, M. (1984): "Job Assignments, Signalling, and Efficiency," RAND Journal of Economics $15(2)$, 255-267.

- (1990): "Up-or-Out Contracts: A Signaling Perspective," Journal of Labor Economics 8(2), $230-250$.

- (1996): "Asymmetric Learning and the Wage/Productivity Relationship," Journal of Economic Behavior \& Organization 31(3), 419-429.

- (2012): "Theory and Evidence in Internal Labor Markets," in The Handbook of Organizational Economics, R. Gibbons and J. Roberts, Eds., Princeton, NJ: Princeton University Press. 


\section{Figure 1. Static Expected Output and Statically Optimal Policies}

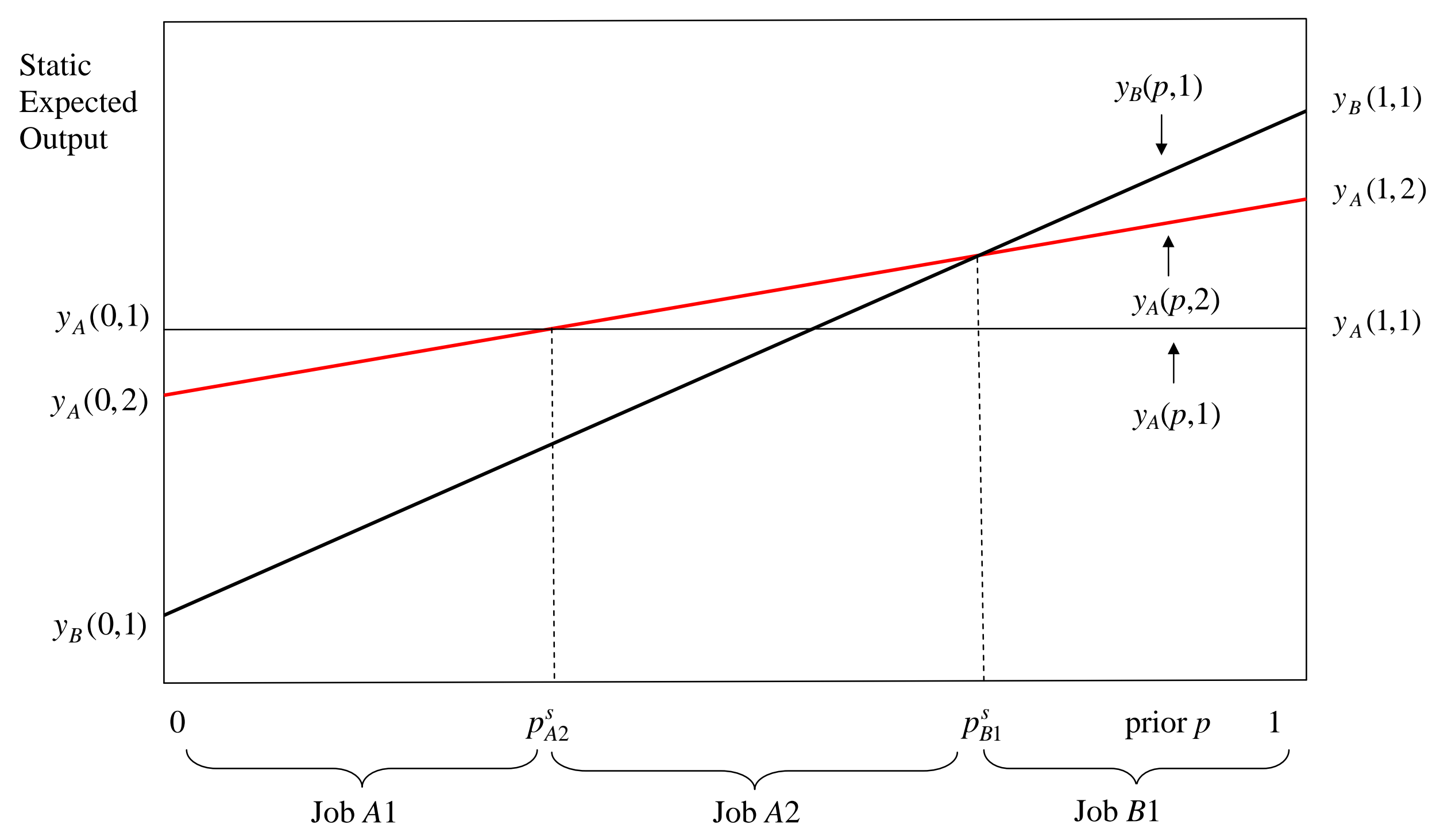




\section{Figure 2. Bayesian Updating in Job $A 2$}

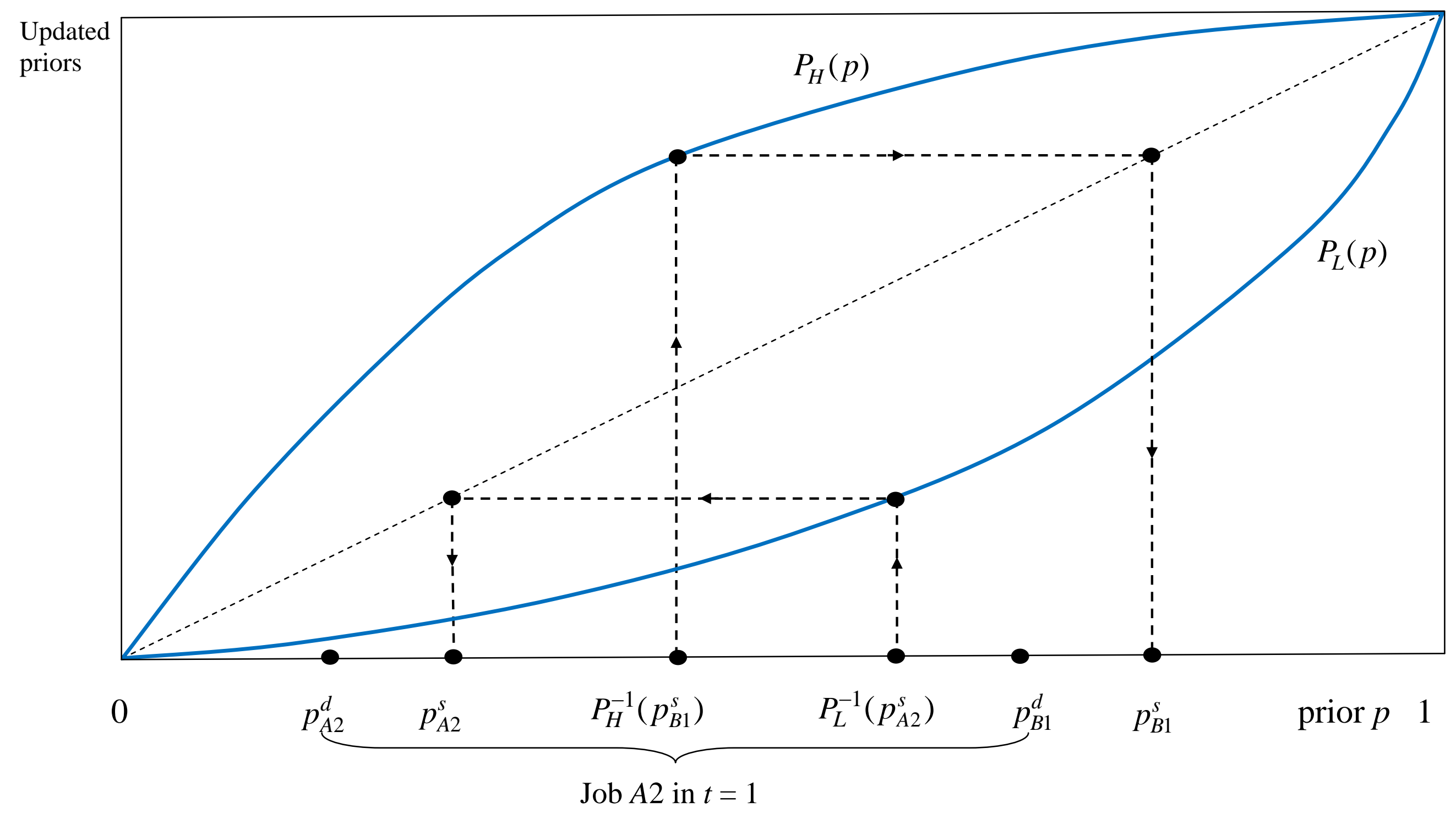

*Note three conditions hold: $P_{H}\left(p_{A 2}^{d}\right)<p_{B 1}^{s}, P_{L}\left(p_{B 1}^{d}\right) \geq p_{A 2}^{s}$, and $P_{H}\left(p_{B 1}^{d}\right) \geq p_{B 1}^{s}$ 


\section{Figure 3. Jobs Assigned in Period 2 After Job A2 in Period 1*}

A. Period 2 Assignment After Success in Job A2 in Period 1

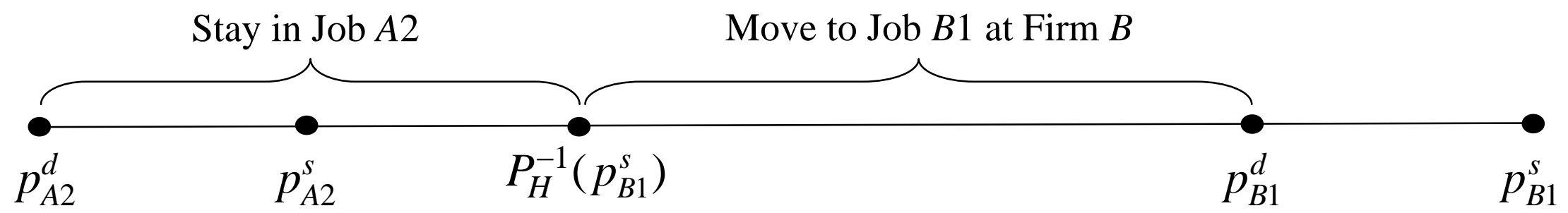

B. Period 2 Assignment After Failure in Job A2 in Period 1

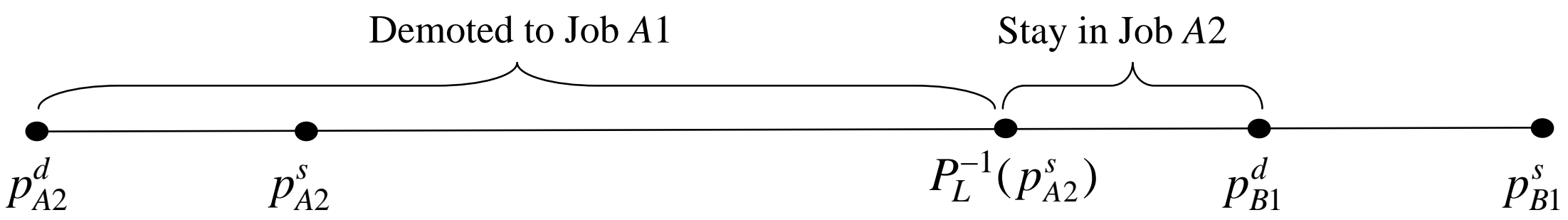

*All workers with priors between $p_{A 2}^{d}$ and $p_{B 1}^{d}$ work in job $A 2$ at firm $A$ in period 1 
TABLE 1

Percentage Distribution of Managers Across Levels by Tenure

\begin{tabular}{|c|c|c|c|c|c|c|c|c|}
\hline \multirow[b]{2}{*}{ Tenure } & \multicolumn{2}{|c|}{ Separation } & \multicolumn{2}{|c|}{ Level 1} & \multicolumn{2}{|c|}{ Level 2} & \multicolumn{2}{|c|}{ Level 3} \\
\hline & Data & Model & Data & Model & Data & Model & Data & Model \\
\hline 1 & 0.0 & 0.0 & 100.0 & 100.0 & 0.0 & 0.0 & 0.0 & 0.0 \\
\hline 2 & 14.5 & 14.5 & 45.6 & 45.7 & 39.9 & 39.8 & 0.0 & 0.0 \\
\hline 3 & 27.7 & 26.5 & 16.8 & 17.2 & 46.8 & 47.3 & 8.7 & 8.9 \\
\hline 4 & 37.9 & 37.1 & 7.6 & 8.1 & 29.2 & 29.2 & 25.3 & 25.6 \\
\hline 5 & 46.1 & 45.3 & 4.6 & 5.3 & 18.1 & 18.3 & 31.1 & 31.2 \\
\hline 6 & 52.0 & 51.5 & 2.9 & 3.4 & 12.3 & 12.6 & 32.8 & 32.5 \\
\hline 7 & 57.6 & 56.9 & 2.1 & 2.7 & 7.7 & 8.3 & 32.6 & 32.1 \\
\hline
\end{tabular}

TABLE 2

Hazard Rates of Separation, Retention at Level, and Promotion (Percentages)

\begin{tabular}{|c|c|c|c|c|c|c|c|}
\hline \multirow[b]{2}{*}{ Level } & \multirow[b]{2}{*}{ Tenure } & \multicolumn{2}{|c|}{ Separated } & \multicolumn{2}{|c|}{ Retained } & \multicolumn{2}{|c|}{ Promoted } \\
\hline & & Data & Model & Data & Model & Data & Model \\
\hline \multirow[t]{6}{*}{ Level 1} & 1 to 2 & 14.5 & 14.5 & 45.6 & 45.7 & 39.9 & 39.8 \\
\hline & 2 to 3 & 14.6 & 14.5 & 36.8 & 20.3 & 48.6 & 55.2 \\
\hline & 3 to 4 & 11.7 & 8.4 & 45.6 & 46.9 & 42.7 & 27.8 \\
\hline & 4 to 5 & 11.9 & 5.0 & 60.6 & 65.0 & 27.5 & 19.9 \\
\hline & 5 to 6 & 9.1 & 5.1 & 62.1 & 64.8 & 28.8 & 21.6 \\
\hline & 6 to 7 & 12.2 & 5.0 & 73.2 & 79.1 & 14.6 & 11.4 \\
\hline \multirow[t]{5}{*}{ Level 2} & 2 to 3 & 16.3 & 13.6 & 61.9 & 55.5 & 21.8 & 10.9 \\
\hline & 3 to 4 & 15.6 & 16.9 & 47.0 & 51.7 & 37.4 & 31.4 \\
\hline & 4 to 5 & 14.7 & 14.2 & 54.8 & 56.9 & 30.5 & 28.9 \\
\hline & 5 to 6 & 12.8 & 12.1 & 60.5 & 62.6 & 26.7 & 25.3 \\
\hline & 6 to 7 & 15.4 & 11.5 & 59.4 & 62.9 & 25.1 & 25.6 \\
\hline \multirow[t]{4}{*}{ Level 3} & 3 to 4 & 10.5 & 12.2 & 89.5 & 87.8 & & \\
\hline & 4 to 5 & 12.2 & 14.2 & 87.8 & 85.8 & & \\
\hline & 5 to 6 & 10.1 & 12.1 & 89.9 & 87.9 & & \\
\hline & 6 to 7 & 10.0 & 11.5 & 90.0 & 88.5 & & \\
\hline
\end{tabular}

TABLE 3

Percentage of High Ratings at Levels 1 and 2

\begin{tabular}{|c|c|c|c|c|}
\hline \multirow[b]{2}{*}{ Tenure } & \multicolumn{2}{|c|}{ Level 1} & \multicolumn{2}{|c|}{ Level 2} \\
\hline & Data & Model & Data & Model \\
\hline 1 & 52.7 & 51.7 & - & - \\
\hline 2 & 34.8 & 34.9 & 58.4 & 56.1 \\
\hline 3 & 19.6 & 21.2 & 43.9 & 42.7 \\
\hline 4 & 11.8 & 11.9 & 26.2 & 30.4 \\
\hline 5 & 2.4 & 6.2 & 18.7 & 20.4 \\
\hline 6 & 3.7 & 3.2 & 12.5 & 13.0 \\
\hline 7 & 0.0 & 1.6 & 13.0 & 8.0 \\
\hline
\end{tabular}


TABLE 4

Percentage Wage Distributions by Level and Tenure*

\begin{tabular}{|c|c|c|c|c|c|c|c|}
\hline \multirow[b]{2}{*}{ Level } & \multirow[b]{2}{*}{ Tenure } & \multicolumn{2}{|c|}{$\begin{array}{c}\text { Between } \\
\$ 20 \mathrm{~K} \text { and } \$ 40 \mathrm{~K}\end{array}$} & \multicolumn{2}{|c|}{$\begin{array}{c}\text { Between } \\
\$ 40 \mathrm{~K} \text { and } \$ 60 \mathrm{~K}\end{array}$} & \multicolumn{2}{|c|}{$\begin{array}{c}\text { Between } \\
\$ 60 \mathrm{~K} \text { and } \$ 80 \mathrm{~K}\end{array}$} \\
\hline & & Data & Model & Data & Model & Data & Model \\
\hline \multirow[t]{7}{*}{ Level 1} & 1 & 59.1 & 57.5 & 40.5 & 42.0 & 0.4 & 0.5 \\
\hline & 2 & 54.4 & 57.4 & 44.8 & 41.7 & 0.8 & 0.8 \\
\hline & 3 & 55.6 & 56.6 & 44.4 & 42.2 & 0.0 & 1.2 \\
\hline & 4 & 53.8 & 56.7 & 46.2 & 41.9 & 0.0 & 1.4 \\
\hline & 5 & 64.1 & 68.1 & 35.9 & 31.1 & 0.0 & 0.7 \\
\hline & 6 & 69.2 & 69.5 & 30.8 & 29.8 & 0.0 & 0.7 \\
\hline & 7 & 75.0 & 70.6 & 25.0 & 28.5 & 0.0 & 0.8 \\
\hline \multirow[t]{6}{*}{ Level 2} & 2 & 35.1 & 34.3 & 63.3 & 63.8 & 1.6 & 1.8 \\
\hline & 3 & 31.3 & 36.1 & 65.7 & 61.7 & 2.9 & 2.2 \\
\hline & 4 & 36.3 & 36.9 & 60.3 & 60.5 & 3.4 & 2.5 \\
\hline & 5 & 37.1 & 37.5 & 59.6 & 59.8 & 3.3 & 2.7 \\
\hline & 6 & 42.4 & 38.1 & 53.3 & 59.0 & 4.2 & 2.9 \\
\hline & 7 & 41.3 & 38.8 & 55.8 & 58.2 & 2.9 & 3.0 \\
\hline \multirow[t]{5}{*}{ Level 3} & 3 & 2.8 & 8.2 & 84.9 & 82.4 & 12.3 & 9.3 \\
\hline & 4 & 4.5 & 10.3 & 85.3 & 80.5 & 10.1 & 9.2 \\
\hline & 5 & 5.3 & 11.3 & 84.2 & 79.1 & 10.5 & 9.5 \\
\hline & 6 & 6.1 & 12.4 & 84.4 & 77.6 & 9.5 & 9.9 \\
\hline & 7 & 4.5 & 13.4 & 81.1 & 76.4 & 14.4 & 10.0 \\
\hline
\end{tabular}

*Mean of wages across tenures: \$39,584 at Level 1, \$43,179 at Level 2, \$48,963 at Level 3. Standard deviation of wages across tenures: \$6,924 at Level 1, \$7,377 at Level 2, \$7,270 at Level 3

TABLE 5

Percentage Distribution of Changes in Log Wage by Tenure

\begin{tabular}{lcccc}
\hline \hline & Between & Between & Between & Growth \\
Tenure & -0.15 and 0.00 & 0.00 and 0.15 & 0.15 and 0.30 & Rate \\
\hline 1 to 2 & 22.9 & 69.9 & 7.2 & 5.2 \\
2 to 3 & 22.6 & 70.4 & 6.6 & 5.1 \\
3 to 4 & 24.9 & 70.3 & 4.3 & 3.9 \\
4 to 5 & 23.6 & 70.1 & 5.9 & 2.2 \\
5 to 6 & 22.5 & 70.5 & 6.9 & 0.7 \\
6 to 7 & 21.9 & 68.5 & 8.3 & 1.8 \\
\hline
\end{tabular}

TABLE 6A

Estimates of Prior Distribution*

\begin{tabular}{lrrrr}
\hline \hline Parameters & Type 1 & Type 2 & Type 3 & Type 4 \\
& $(i=1)$ & $(i=2)$ & $(i=3)$ & $(i=4)$ \\
\hline Prior: $\varphi_{i 1}$ & -0.672 & -0.484 & -0.141 & 0.435 \\
& $(0.022)$ & $(0.021)$ & $(0.017)$ & $(0.022)$ \\
Mass: $q_{i}$ & 0.155 & 0.211 & 0.313 & NA \\
& $(0.017)$ & $(0.030)$ & $(0.076)$ & \\
\hline
\end{tabular}

*I let $p_{i 1}=\exp \left\{\varphi_{i 1}\right\} /\left[1+\exp \left\{\varphi_{i 1}\right\}\right]$ and estimate $\varphi_{i 1}: p_{11}=0.338, p_{21}=0.381, p_{31}=0.465, p_{41}=$ 0.607. Asymptotic standard errors in parentheses 
TABLE 6B

Estimates of Learning Parameters*

\begin{tabular}{lrrr}
\hline \hline Parameters & Level 1 $(k=1)$ & Level 2 $(k=2)$ & Level 3 $(k=3)$ \\
\hline High Ability: $\alpha_{k}$ & 0.514 & 0.5437 & 0.5435 \\
& $(0.062)$ & $(0.006)$ & $(0.007)$ \\
Low Ability: $\beta_{k}$ & 0.456 & 0.491 & 0.490 \\
& $(0.014)$ & $(0.013)$ & $(0.010)$ \\
\hline
\end{tabular}

*Asymptotic standard errors in parentheses

TABLE 6C

Estimates of Classification Error in Performance Ratings*

\begin{tabular}{lrrr}
\hline \hline Parameters & Level $1(k=1)$ & Level 2 $(k=2)$ & Level 3 \\
\hline Base error: $d_{0}$ & 0.521 & $($ same $)$ & NA \\
Persistence: $d_{2}(L k)$ & $(0.040)$ & $($ same $)$ & \\
& -0.703 & -0.544 & NA \\
& $(0.040)$ & $(0.029)$ & \\
\hline
\end{tabular}

*See Appendix A.2. Asymptotic standard errors in parentheses

TABLE 6D

Estimates of Output and Human Capital: Intercepts $\left(b_{k t}\left(k_{t-1}\right)\right)$ and Slopes $\left(c_{k t}\right)^{*}$

\begin{tabular}{lrr}
\hline \hline Parameters & Value & St. Error \\
\hline Level $1(k=1)$ & & \\
$b_{14}(L 2)-b_{14}(L 1)$ & -704.735 & 3.577 \\
$b_{15}(L 2)-b_{15}(L 1)$ & -479.607 & 3.232 \\
$c_{12}$ & $2,960.515$ & 13.719 \\
Level $2(k=2)$ & & \\
$c_{22}$ & $2,563.449$ & 5.570 \\
$c_{23}$ & $2,210.102$ & 8.950 \\
$c_{25}$ & $2,171.916$ & 8.388 \\
$c_{26}$ & $2,224.791$ & 5.423 \\
Level 3 $(k=3)$ & & \\
$b_{34}(L 3)-b_{34}(L 2)$ & 853.477 & 5.941 \\
$b_{35}(L 3)-b_{35}(L 2)$ & 202.791 & 4.475 \\
$b_{37}(L 3)-b_{37}(L 2)$ & 228.069 & 2.715 \\
$c_{31}$ & -399.955 & 9.659 \\
$c_{34}$ & $2,963.404$ & 15.229 \\
$c_{37}$ & $2,190.704$ & 1.041 \\
$c_{38}$ & $2,003.340$ & 1.066 \\
\hline
\end{tabular}

*See Appendix A.2: $b_{11}=1,000, b_{15}(L 2)-b_{15}(L 1)=b_{1 t}(L 2)-b_{1 t}(L 1), t=6,7 ; b_{2 t}\left(k_{t-}\right.$ $\left.{ }_{1}\right)=0, c_{24}=c_{22}, c_{27}=c_{26} ; b_{35}(L 3)-b_{35}(L 2)=b_{36}(L 3)-b_{36}(L 2), c_{33}=c_{32}=c_{31}, c_{35}=$ $c_{36}=c_{22}$. Due to the small number of job transitions at certain tenures, all other parameters have been set equal to their values at the best competitor, which are normalized to zero 
TABLE 6E

Estimates of Separation Shocks $\left(\eta_{k t}\right)^{*}$

\begin{tabular}{|c|c|c|}
\hline Parameters & Value & St. Error \\
\hline \multicolumn{3}{|c|}{ Level $1(k=1)$} \\
\hline$\eta_{11}$ & 0.145 & 0.004 \\
\hline$\eta_{13}\left(\xi_{3}\right)$ & 0.033 & 0.001 \\
\hline$\eta_{14}$ & 0.050 & 0.0001 \\
\hline \multicolumn{3}{|c|}{ Level $2(k=2)$} \\
\hline$\eta_{21}$ & 0.136 & 0.002 \\
\hline$\eta_{24}$ & 0.142 & 0.001 \\
\hline$\eta_{25}$ & 0.121 & 0.001 \\
\hline$\eta_{26}$ & 0.115 & 0.0003 \\
\hline$\eta_{27}$ & 0.111 & 0.0003 \\
\hline \multicolumn{3}{|c|}{ Level $3(k=3)$} \\
\hline$\eta_{31}$ & 0.122 & 0.002 \\
\hline
\end{tabular}

TABLE 6F

Estimates of Wages: Type-Specific Intercept $\left(\varpi_{0 i k}\right)$ of the Wage Equation*

\begin{tabular}{lrrrr}
\hline \hline Parameters & Type 1 & Type 2 & Type 3 & Type 4 \\
& $(i=1)$ & $(i=2)$ & $(i=3)$ & $(i=4)$ \\
\hline Level 1: $\varpi_{0 i 1}$ & 8.805 & 9.288 & 9.213 & 8.865 \\
& $(0.005)$ & $(0.005)$ & $(0.011)$ & $(0.013)$ \\
Level 2: $\varpi_{0 i 2}$ & 8.969 & 9.359 & 9.281 & 8.945 \\
& $(0.004)$ & $(0.004)$ & $(0.009)$ & $(0.012)$ \\
Level 3: $\varpi_{0 i 3}$ & 9.534 & 9.813 & 9.738 & 9.418 \\
& $(0.008)$ & $(0.004)$ & $(0.007)$ & $(0.011)$ \\
\hline
\end{tabular}

*See Appendix A.2. Asymptotic standard errors in parentheses

TABLE 6G

Estimates of Wages: Effect of Age, Education, and Tenure (Common Across Types)*

\begin{tabular}{lrr}
\hline \hline Parameters & Value & St. Error \\
\hline Levels 1 and 2 & & \\
Age: $\varpi_{1}$ & 0.028 & 0.0001 \\
Age $: \varpi_{2}$ & -0.0003 & 0.000002 \\
Edu: $\varpi_{3}$ & 0.022 & 0.0004 \\
Level 1 & & \\
$\quad$ Tenure: $\omega_{12}$ & 0.007 & 0.0003 \\
Level 3 & & \\
Age: $\varpi_{13}$ & 0.010 & 0.001 \\
Age $\varpi_{23}$ & -0.0001 & 0.00001 \\
Edu: $\varpi_{33}$ & 0.021 & 0.001 \\
\hline
\end{tabular}

*See Appendix A.2 
TABLE 6H

Estimates of Wages: Year Dummies $\varpi_{y m}$ (Baseline: 1970-1973)*

\begin{tabular}{lrrrrr}
\hline \hline Parameters & 1975 & 1976 & 1977 & 1978 & 1979 \\
& $\left(\varpi_{y 5}\right)$ & $\left(\varpi_{y 6}\right)$ & $\left(\varpi_{y 7}\right)$ & $\left(\varpi_{y 8}\right)$ & $\left(\varpi_{y 9}\right)$ \\
\hline \multirow{2}{*}{$\varpi_{y m}$} & -0.063 & -0.107 & -0.140 & -0.208 & -0.169 \\
& $(0.003)$ & $(0.004)$ & $(0.004)$ & $(0.003)$ & $(0.003)$ \\
\hline
\end{tabular}

*See Appendix A.2: $\varpi_{y 4}=\varpi_{y 5}$. Asymptotic standard errors in parentheses

TABLE 6I

Estimates of Wages: Coefficients on Prior $\left(\varpi_{2}\right)$ and Standard Deviations $\left(\sigma_{i k}\right)^{*}$

\begin{tabular}{lrrrr}
\hline \hline Parameters & $\begin{array}{r}\text { Type } 1 \\
(i=1)\end{array}$ & $\begin{array}{r}\text { Type 2 } \\
(i=2)\end{array}$ & $\begin{array}{r}\text { Type 3 } \\
(i=3)\end{array}$ & $\begin{array}{r}\text { Type 4 } \\
(i=4)\end{array}$ \\
\hline Prior: $\omega_{2 i}$ & 2.371 & 1.833 & 1.316 & 1.364 \\
& $(0.045)$ & $(0.027)$ & $(0.015)$ & $(0.010)$ \\
Level 1: $\sigma_{i 1}$ & 0.076 & 0.070 & 0.057 & 0.044 \\
& $(0.001)$ & $(0.001)$ & $(0.001)$ & $(0.001)$ \\
Level 2: $\sigma_{i 2}$ & 0.063 & 0.047 & 0.0302 & 0.0303 \\
& $(0.001)$ & $(0.001)$ & $(0.0004)$ & $(0.0004)$ \\
Level 3: $\sigma_{i 3}$ & 0.047 & (as Type 1) & (as Type 1) & (as Type 1) \\
& $(0.0004)$ & (as Type 1) & (as Type 1) & (as Type 1) \\
\hline
\end{tabular}

*Asymptotic standard errors in parentheses

TABLE 7A

Counterfactual Experiments: Importance of Learning for Wages Baseline, No Learning, Fast Learning at Level 1, Fast Learning at Level 2* Wages in Each Case

Fast Learning at

Statistic Baseline No Learning No Experimenta- Level 1

Level 2 tion

Means by Level

Level 1

Level 2

$\$ 39,584$

43,179

$\$ 39,706$

43,070

$\$ 39,763$

42,600

$\$ 58,271$

61,451

48,818

44,623

$\$ 37,847$

48,454

$\$ 6,791$

6,464

$\$ 6,902$

6,831

$\$ 35,961$

51,466

45,784

77,503

24,360

Standard Deviations by Level

Level 2

7,077

6,534

7,971

$3.3 \%$

$0.9 \%$

6.8

17.6

9.8

20.5

11.1

21.6

12.9

22.1

Tenure 6

15.9

17.5

14.6

22.2

15.4

23.3

$39.3 \%$

48.5

52.8

55.4

58.1

19.4

60.6

62.5

$\$ 8,668$

45,057

4,281

Tenure 7 (Balanced Panel)

*No Learning: $\beta_{k}=\hat{\alpha}_{k}, k=1,2,3$; Fast Learning at Level $k$ : $\alpha_{\mathrm{k}}=0.99$ and $\beta_{\mathrm{k}}=0.01, k=1,2$ 
TABLE 7B

Counterfactual Experiments: Importance of Learning for Level Assignments

Baseline, No Learning, Fast Learning at Level 1, Fast Learning at Level 2*

\begin{tabular}{|c|c|c|c|c|c|c|c|c|c|c|c|c|c|c|c|c|}
\hline \multirow[b]{2}{*}{ Tenure } & \multicolumn{4}{|c|}{ Separation } & \multicolumn{4}{|c|}{ Level 1} & \multicolumn{4}{|c|}{ Level 2} & \multicolumn{4}{|c|}{ Level 3} \\
\hline & Base. & No L & $\begin{array}{c}\text { Fast L } \\
\text { at } 1 \\
\end{array}$ & $\begin{array}{c}\text { Fast L } \\
\text { at } 2 \\
\end{array}$ & Base. & No L & $\begin{array}{c}\text { Fast L } \\
\text { at } 1 \\
\end{array}$ & $\begin{array}{c}\text { Fast L } \\
\text { at } 2 \\
\end{array}$ & Base. & No L & $\begin{array}{c}\text { Fast L } \\
\text { at } 1 \\
\end{array}$ & $\begin{array}{c}\text { Fast L } \\
\text { at } 2 \\
\end{array}$ & Base. & No L & $\begin{array}{c}\text { Fast L } \\
\text { at } 1 \\
\end{array}$ & $\begin{array}{c}\text { Fast L } \\
\text { at } 2 \\
\end{array}$ \\
\hline 1 & 0.0 & 0.0 & 0.0 & 0.0 & 100.0 & 100.0 & 100.0 & 100.0 & 0.0 & 0.0 & 0.0 & 0.0 & 0.0 & 0.0 & 0.0 & 0.0 \\
\hline 2 & 14.5 & 14.5 & 14.5 & 14.5 & 45.7 & 57.7 & 40.5 & 0.0 & 39.8 & 27.8 & 45.0 & 85.4 & 0.0 & 0.0 & 0.0 & 0.0 \\
\hline 3 & 26.5 & 26.6 & 26.5 & 26.1 & 17.2 & 20.6 & 14.6 & 5.0 & 47.3 & 52.0 & 38.9 & 35.0 & 8.9 & 0.8 & 20.0 & 33.8 \\
\hline 4 & 37.1 & 37.3 & 36.7 & 36.6 & 8.1 & 11.6 & 7.3 & 2.0 & 29.2 & 40.3 & 25.9 & 29.1 & 25.6 & 10.8 & 30.1 & 32.3 \\
\hline 5 & 45.3 & 45.1 & 45.0 & 45.4 & 5.3 & 8.2 & 4.9 & 1.3 & 18.3 & 30.3 & 17.7 & 24.7 & 31.2 & 16.4 & 32.4 & 28.6 \\
\hline 7 & 56.9 & 56.4 & 56.7 & 57.4 & 2.7 & 4.5 & 2.6 & 0.9 & 8.3 & 15.4 & 8.7 & 19.2 & 32.1 & 23.6 & 32.0 & 22.6 \\
\hline
\end{tabular}

*No Learning: $\beta_{k}=\hat{\alpha}_{k}, k=1,2,3$; Fast Learning at Level $k$ : $\alpha_{\mathrm{k}}=0.99$ and $\beta_{\mathrm{k}}=0.01, k=1,2$

TABLE 7C

Counterfactual Experiment: Importance of Experimentation for Level Assignments Baseline and Equal Informativeness as Level 1*

\begin{tabular}{|c|c|c|c|c|c|c|c|c|}
\hline \multirow[b]{2}{*}{ Tenure } & \multicolumn{2}{|c|}{ Separation } & \multicolumn{2}{|c|}{ Level 1} & \multicolumn{2}{|c|}{ Level 2} & \multicolumn{2}{|c|}{ Level 3} \\
\hline & Base. & $\begin{array}{c}\text { Equal Info. } \\
\text { As L1 }\end{array}$ & Base. & $\begin{array}{c}\text { Equal Info. } \\
\text { As L1 }\end{array}$ & Base. & $\begin{array}{c}\text { Equal Info. } \\
\text { As L1 }\end{array}$ & Base. & $\begin{array}{c}\text { Equal Info. } \\
\text { As L1 } \\
\end{array}$ \\
\hline 1 & 0.0 & 0.0 & 100.0 & 100.0 & 0.0 & 0.0 & 0.0 & 0.0 \\
\hline 2 & 14.5 & 14.5 & 45.7 & 84.6 & 39.8 & 0.9 & 0.0 & 0.0 \\
\hline 3 & 26.5 & 26.9 & 17.2 & 6.2 & 47.3 & 18.3 & 8.9 & 48.6 \\
\hline 4 & 37.1 & 36.4 & 8.1 & 2.0 & 29.2 & 7.7 & 25.6 & 53.8 \\
\hline 7 & 56.9 & 57.3 & 2.7 & 0.5 & 8.3 & 1.3 & 32.1 & 40.9 \\
\hline
\end{tabular}

*Equal Informativeness as Level 1: $\alpha_{k}=\hat{\alpha}_{1}, \beta_{k}=\hat{\beta}_{1}, k=2,3$ 